\title{
Review \\ Genome Scale Modeling to Study the Metabolic Competition between Cells in the Tumor Microenvironment
}

\author{
Itziar Frades ${ }^{1}$, Carles Foguet ${ }^{2,3}\left(\mathbb{D}\right.$, , Marta Cascante ${ }^{2,3}(\mathbb{D})$ and Marcos J. Araúzo-Bravo ${ }^{1,4,5,6,7, *(\mathbb{D})}$ \\ 1 Computational Biology and Systems Biomedicine Group, Biodonostia Health Research Institute, \\ 20009 San Sebastian, Spain; itziar.frades@biodonostia.org \\ 2 Department of Biochemistry and Molecular Biomedicine, Institute of Biomedicine of University of Barcelona, \\ Faculty of Biology, Universitat de Barcelona, Av. Diagonal 643, 08028 Barcelona, Spain; cfoguet@ub.edu (C.F.); \\ martacascante@ub.edu (M.C.) \\ 3 Centro de Investigación Biomédica en Red de Enfermedades Hepáticas y \\ Digestivas (CIBEREHD) (CB17/04/00023) and Metabolomics Node at Spanish National Bioinformatics \\ Institute (INB-ISCIII-ES-ELIXIR), Instituto de Salud Carlos III (ISCIII), 28020 Madrid, Spain \\ 4 Max Planck Institute of Molecular Biomedicine, 48167 Münster, Germany \\ 5 Centro de Investigación Biomédica en Red de Fragilidad y Envejecimiento Saludable (CIBERfes), \\ 28015 Madrid, Spain \\ 6 Translational Bioinformatics Network (TransBioNet), 8001 Barcelona, Spain \\ 7 Ikerbasque, Basque Foundation for Science, 48012 Bilbao, Spain \\ * Correspondence: marcos.arauzo@biodonostia.org; Tel.: +34-943-00-6108
}

check for

updates

Citation: Frades, I.; Foguet, C.; Cascante, M.; Araúzo-Bravo, M.J. Genome Scale Modeling to Study the Metabolic Competition between Cells in the Tumor Microenvironment. Cancers 2021, 13, 4609. https: / / doi.org/10.3390/cancers13184609

Academic Editors: Andrei Zinovyev,

Laurence Calzone and

Inna Kuperstein

Received: 6 August 2021

Accepted: 9 September 2021

Published: 14 September 2021

Publisher's Note: MDPI stays neutral with regard to jurisdictional claims in published maps and institutional affiliations.

Copyright: (c) 2021 by the authors. Licensee MDPI, Basel, Switzerland. This article is an open access article distributed under the terms and conditions of the Creative Commons Attribution (CC BY) license (https:/ / creativecommons.org/licenses/by/ $4.0 /)$.
Simple Summary: Immune and cancer cells compete for nutrients within the tumor microenvironment, leading to a metabolic battle between these cell populations. In this battle, tumor cells reprogram their metabolism for a high demand of building blocks and energy and to gain advantages over immune cells. To study these mechanisms, we require the quantification of metabolic fluxes, which can be estimated at the genome-scale, with constraint-based or kinetic modeling.

Abstract: The tumor's physiology emerges from the dynamic interplay of numerous cell types, such as cancer cells, immune cells and stromal cells, within the tumor microenvironment. Immune and cancer cells compete for nutrients within the tumor microenvironment, leading to a metabolic battle between these cell populations. Tumor cells can reprogram their metabolism to meet the high demand of building blocks and ATP for proliferation, and to gain an advantage over the action of immune cells. The study of the metabolic reprogramming mechanisms underlying cancer requires the quantification of metabolic fluxes which can be estimated at the genome-scale with constraint-based or kinetic modeling. Constraint-based models use a set of linear constraints to simulate steady-state metabolic fluxes, whereas kinetic models can simulate both the transient behavior and steady-state values of cellular fluxes and concentrations. The integration of cell- or tissue-specific data enables the construction of context-specific models that reflect cell-type- or tissue-specific metabolic properties. While the available modeling frameworks enable limited modeling of the metabolic crosstalk between tumor and immune cells in the tumor stroma, future developments will likely involve new hybrid kinetic/stoichiometric formulations.

Keywords: metabolic reprogramming in cancer; immune system; genome-scale metabolic models; constraint-based modeling; stoichiometric models; kinetic metabolic models; metabolic crosstalk

\section{Introduction}

Tumors have a pseudo-organ-like dynamism with numerous cell types that interact to create a unique physiology [1]. The cell types within the tumor microenvironment (TME) include cancer cells, immune cells and stromal cells (Figure 1), and they play a key role in the progression of the disease [2]. Immune response can potentially lead to the destruction of cancer cells; however, tumors often evade the host's immune system through different 
mechanisms [3]. Indeed, the dynamic interplay between tumor, stroma and immune system can lead to both pro-tumorigenic and anti-tumorigenic behaviors $[4,5]$. At the metabolic level, there is a battle between immune and cancer cells where they compete for nutrients within the TME. Cancer cells reprogram their metabolism to have an increased nutrient uptake from the TME, which limits the availability of nutrients for immune cell populations, weakening, corrupting and evading immunosurveillance [6].

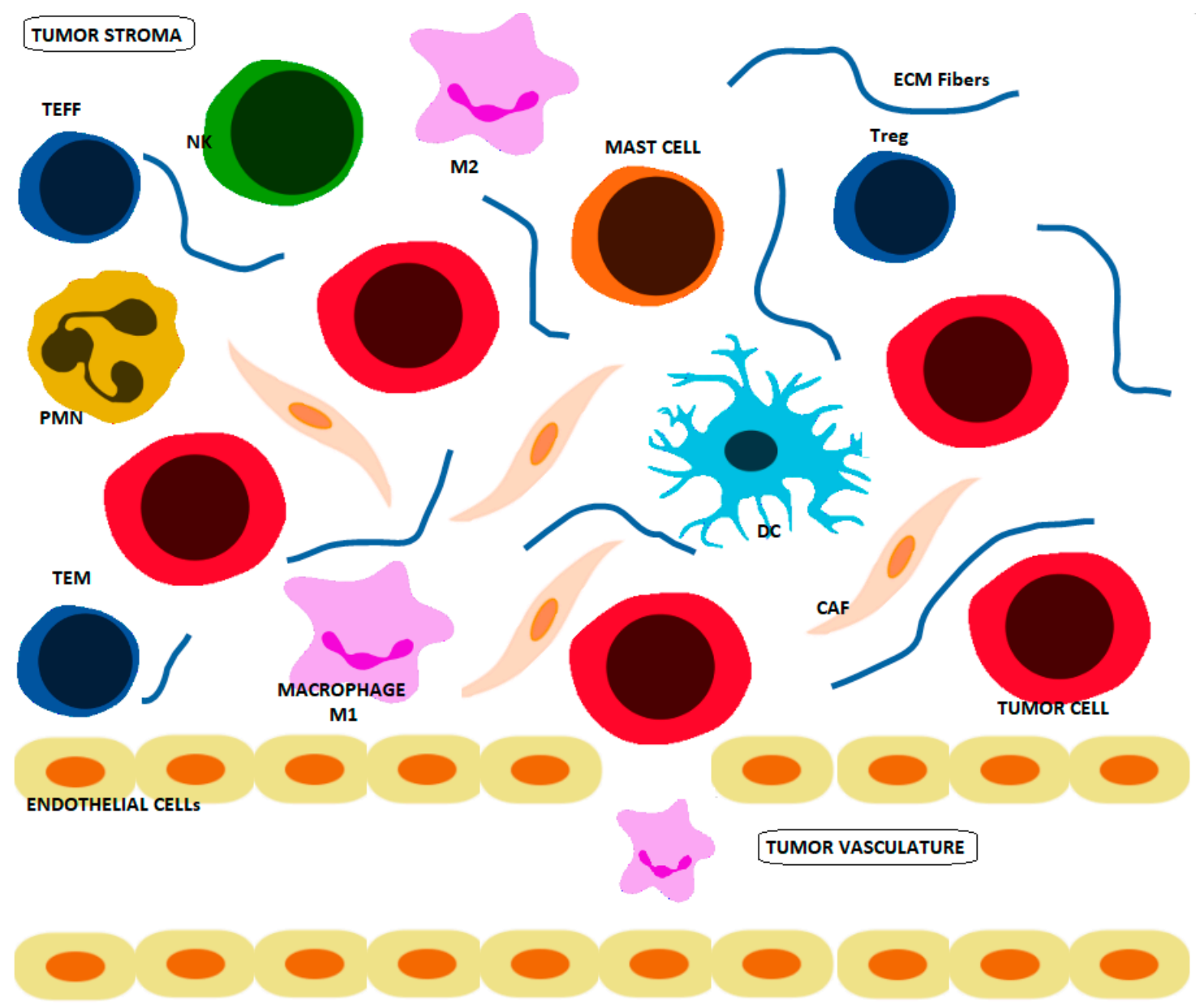

Figure 1. The cell types within the TME include cancer cells, immune cells and stromal cells. The immune cells in the TME include natural killer (NK) cells, dendritic cells (DC), macrophages (M1 and M2), polymorphonuclear leukocytes (PMN) (including neutrophils, eosinophils and basophils), mast cells and T cells (Regulatory T cells (Tregs), effector T cells (TEFF) and memory T cells (TMEM)). The stromal cells include cancer-associated fibroblasts (CAFs), which are embedded in the TME with Extracellular Matrix (ECM) fibers.

The immune effectors against cancer are natural killer cells (NK), dendritic cells (DC), macrophages, polymorphonuclear leukocytes (PMN) (neutrophils, eosinophils and basophils), mast cells and T cells (lymphocytes B and cytotoxic T lymphocytes). NK cells, DC, PMN, mast cells and macrophages constitute the first-line effectors to cancer cells (Figure 1). NK cells participate in the innate and adaptive immune response through close interactions with $\mathrm{T}$ lymphocytes with cytotoxic effects and memory [6].

Based on the expression of cell surface markers T cells are classified into CD4+ helper $\mathrm{T}$ (TH) and CD8+ cytotoxic T (TC) functional cell lineages. TH cells bind to the class II major histocompatibility complex (MHC) molecules and help the immune system recognize foreign substances to modulate the immune response and to produce cytokines to enhance or suppress inflammation [7]. TC cells target pathogen-infected or malignant cells by secreting inflammatory cytokines, as well as cytotoxic proteins that act as cell lytic molecules, such as the pore-forming protein perforin, which facilitates the entry of the inducing apoptosis 
granzyme in the target-cell membrane. TH cells circulate through the body, and they are activated when recognize an antigen presented by the antigen-presenting cell (APC). Antigen-presenting starts with the ingestion of the foreign particles by the APC; then the particles are degraded and exported to the cell surface, with the resulting antigens, where they are presented in association with molecules from the class II MHC. Upon activation, $\mathrm{TH}$ cell populations expand and release several immunomodulating cytokines [8]. TC cells travel through the blood flow, searching for antigens that are presented by MHC Class I to the T-Cell Receptor (TCR). The activation of these cells required several interactions between the molecules they express on the surface, the molecules on the surface of the APCs and DCs [9].

The TC activation requires two signals: a first signal the TCR binds to the MHC class I molecule, and a second signal assisted by stimulating the CD28 molecule on the TC with cytokines released from TH cells. Then, using IL-2 acting as a growth and differentiation factor for the TC, the TC clonally expand, increasing the cells that recognize the antigen [10].

Before encountering an antigen, $\mathrm{T}$ cells are called $\mathrm{T}$ naïve (TN) and after antigen encounter, $\mathrm{T}$ cells are activated. Regulatory $\mathrm{T}$ cells (Tregs) emerge from the acquisition of immuno-suppressive characteristics of the TH cells. TC cells can differentiate from TN to stem central memory T cells (TSCM), to central memory T cells (TCM), effector memory T (TEM) or effector T cells (TEFF). All of these cells finally converge in terminally differentiated effector memory cells re-expressing CD45RA (TEMRA) [7]. TN cells usually express CD45RA cell-surface antigen isoform when activated; T cells, such as TCM and TEM cells, switch from expressing isoform CD45RA to the isoform CD45RO [11,12], whereas TEMRAs, such as TN cells, re-express CD45RA [13].

Memory T cells can be CD4+ or CD8+ and are TEM or TCM subtype depending on the set of cell surface markers they express. All of them are long-lived and capable of expanding quickly when re-exposed to their corresponding antigen, which provides a controlled immune response against previously encountered foreign bodies.

$\mathrm{T}$ cells rewire their metabolism to promote these changes. TN cells primarily rely on glucose respiration and oxidative phosphorylation (OXPHOS) to meet their energy needs. Upon recognizing an antigen, activated T cells differentiate to TEFF and switch to aerobic glycolysis, increasing both glucose and glutamine uptake [14]. Once the antigen is cleared, memory $\mathrm{T}$ cells switch to fatty acid oxidation (FAO) as their primary energy source [14]. Similarly, Tregs mainly depend on OXPHOS and FAO [15]. T cells become exhausted when they fail to clear antigens. T lymphocytes derived from tumors show elevated levels of PD-1 (Programmed Cell Death-1), decreasing the PI3K/Akt/mTOR signaling pathway's activity. PD-1 and PD-L1 (Programmed Death-Ligand 1) belong to the family of immune checkpoint proteins that modulate the T-cell response [16]. The PD-1/PD-L1 interaction ensures that the immune system is activated only at the appropriate time in order to avoid chronic autoimmune inflammation and represents an adaptive immune resistance mechanism of tumor cells in response to endogenous immune antitumor activity [17]. Indeed, tumor cells often overexpress PD-L1, which binds to the activated T cells' PD-1 receptors and inhibits their cytotoxic activity [18]. Exhausted T cells in tumors with elevated levels of PD-1 are unable to uptake nutrients, such as glucose and glutamine; therefore, even if they often have dysfunctional mitochondria and decreased mitochondrial mass, they rely on FAO [14,19] (Figure 2). It has been suggested that the degree of T-cell exhaustion induced by PD-1 might depend on the reserves of endogenous lipids that can be mobilized for energy generation [20].

The metabolic phenotype of cancer cells reflects the characteristics of any proliferating cell; thus, cancer and immune cells have similar metabolic requirements [21], and the metabolism is responsible for many of the pathophysiologic interactions that occur within the TME, including the symbiotic nutrient sharing, competition for nutrients and usage of metabolites as signaling molecules [1]. A full understanding of the metabolic phenotype and crosstalk between cancer cells and immune cell populations requires tracing metabolic fluxes (i.e., the rate at which metabolites are interconverted through metabolic reactions 
and transported across cellular membranes). In this regard, over the last decade, GenomeScale Models (GEMs) have emerged as platforms where multiple layers of data can be integrated to estimate the underlying flux maps at a genome-scale. Thus, in addition to other aims, GEMs can be applied to the study of the interactions of cancer cells with the surrounding cells from the TME [22], as well as predicting [23] and circumventing the drug resistance [24].

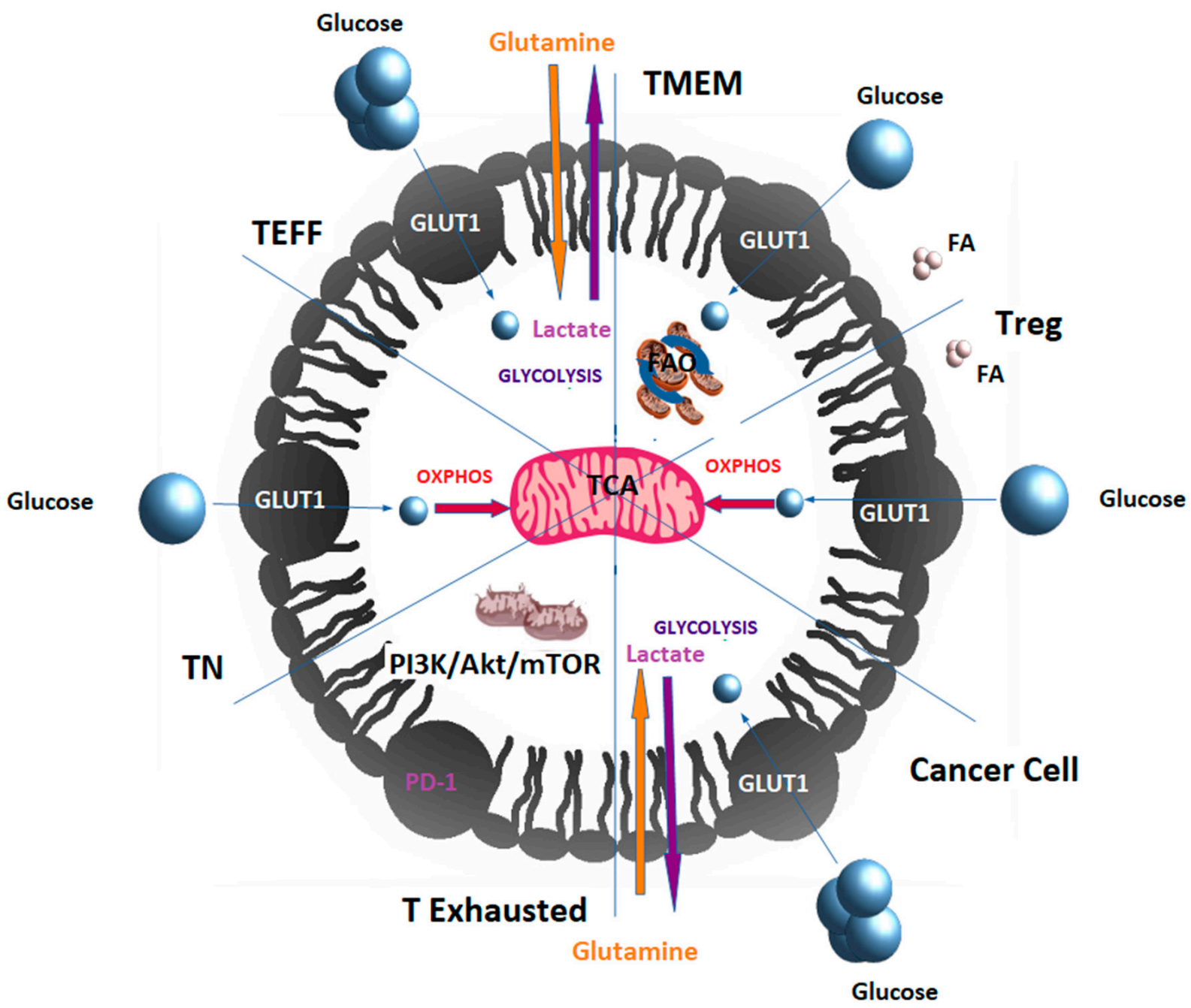

Figure 2. T cells remodel their metabolism to get differentiated into T-cell subsets within the TME. TN cells use glucose that enters in OXPHOS. Upon encountering cognate antigen, activated T cells get differentiated into TEFF, rapidly uptaking glucose and glutamine to perform aerobic glycolysis and generating lactate as a by-product. Once the antigen is cleared, TEFFs can get differentiated into memory T cells (TMEM), which depend on fatty acid oxidation. Equally, cancer cells depend on aerobic glycolysis and glutaminolysis that are fueled by glucose and glutamine, respectively, with production of lactate as a by-product. TEFF within the TME can be differentiated into Tregs with immunosuppressive properties that mainly produce energy by oxidative phosphorylation (OXPHOS) and fatty acid oxidation (FAO). T cells can become exhausted if they fail to clear antigens, as, for example, in cancer. T lymphocytes derived from tumors show elevated levels of PD-1 decreasing PI3K/Akt/mTOR signaling pathway and therefore glycolysis. Exhausted T cells in tumors having often dysfunctional mitochondria rely on FAO. FA: fatty acids. Cancer cells and T cells compete for nutrients, since cancer cells also have an increased glucose and glutamine uptake and they use aerobic glycolysis with production of lactate that is exported to the extracellular space, promoting acidification in the TME that compromises the activity of immune cells.

\subsection{Crosstalk between Cancer and Immune Cells}

Metabolic reprogramming and immune escape are two major hallmarks of cancer cells. Metabolic reprogramming is not only indispensable for sustaining tumorigenesis 
but also for maintaining homeostasis of immune cells. Immune and tumor cells compete for metabolic resources within the TME, as they share metabolic needs. However, compared with immune cells, cancer cells show greater plasticity to reshape their metabolism to circumvent the adverse conditions and increase the ability to capture and exploit the limited metabolites available within the TME. This leads to an interaction between tumor and immune cells that results in a metabolic competition within TME that limits nutrient disposition and conditions the function of immune cells and often results in immunosuppression $[25,26]$. Indeed, cancer metabolic reprograming creates a metabolically hostile TME in which immune cells acquire functional defects and enter a hyporesponsive (or anergic) reversible state, with impaired effector capacities even favoring tumor progression [27]. Local nutrient depletion or production of metabolic "waste" products can affect immune cells contributing to immune evasion in several ways (Figure 3) [28]. In this regard, it has been identified critical differences between immune and tumor cells which may be exploited to treat cancer [21]. Thus, the blocking of tumor-mediated immunosuppression, the tailoring of immune responses by manipulating cellular metabolic pathways and the identification of new targets have proven to have a very positive impact in clinical oncology [15,29].

Cancer triggers immune escape thought several mechanisms including reduced expression of antigens at the surface of tumor cells, reduced expression of MHC molecules by APCs, impaired co-localization of TCR and co-stimulatory receptors, secretion of inhibitory cytokines and activation of inhibitory receptors on T-cell surface, as well as metabolic rewiring [30]. The influence of metabolic determinants on the regulation of immune cells plasticity and function are still to be fully elucidated. Emerging evidence suggests that metabolic crosstalk between cancer and immune cells can strongly contribute to immune suppression and can even facilitate cancer progression $[6,14,28]$. Since the loss of physiological regulation in cancer cells is associated with increased metabolic demand and each type of immune cell has distinct metabolic requirements that restrict or alter cell fate, the interaction of cancer cells and immune cells is subject to a significant plasticity to engage metabolic programs that modulate metabolite levels and consequently their function and fate [21]. Consequently, metabolic pathophysiologic interactions in the TME that drive cancer progression derive from autonomous malignant cells alone or with interacting cells rewiring their metabolic properties. The main metabolic reprogrammed properties that dictate the course of the disease are related to the Warburg effect, the acidification of the TME, the mutations that alter the availability of certain amino acids, hypoxia, the metabolite-sensing-induced mechanisms, the macromolecules and organelles released in the TME and the reverse Warburg effect.

\subsubsection{Warburg Effect}

Even in the presence of oxygen and fully functioning mitochondria, tumor cells preferentially use aerobic glycolysis instead of oxidative phosphorylation, which supports the production of building blocks, reductive power and ATP for proliferating cells, but it has lower ATP yield per molecule of substrate, a phenomenon termed the Warburg effect [31]. This metabolic adaptation is regulated by a number of oncogenes and tumor suppressor genes, such as PI3K/Akt/mTOR signaling pathway, C-MYC and hypoxia inducible factor (HIF) [32].

Glucose and glutamine are the main substrates of cancer cells; thus, their uptake is increased in cancer. Glutamine metabolism is mainly driven by the C-MYC oncogene, a proto-oncogene often constitutively overexpressed in cancer, which increases the expression of glutamine transporters and their metabolic enzymes [21,27] (Domblides et al. 2019). C-MYC, also promotes activation of glycolytic genes and glucose transporters [33]. In this regard, cancer cells often overactivate mTOR, which upregulates the translocation of the glucose transporter GLUT1 to the plasma membrane [27]. PI3K/Akt/mTOR pathway activity is frequently upregulated in cancer as it is involved in the regulation of cell proliferation, growth, cell size, metabolism, and motility [21]. 


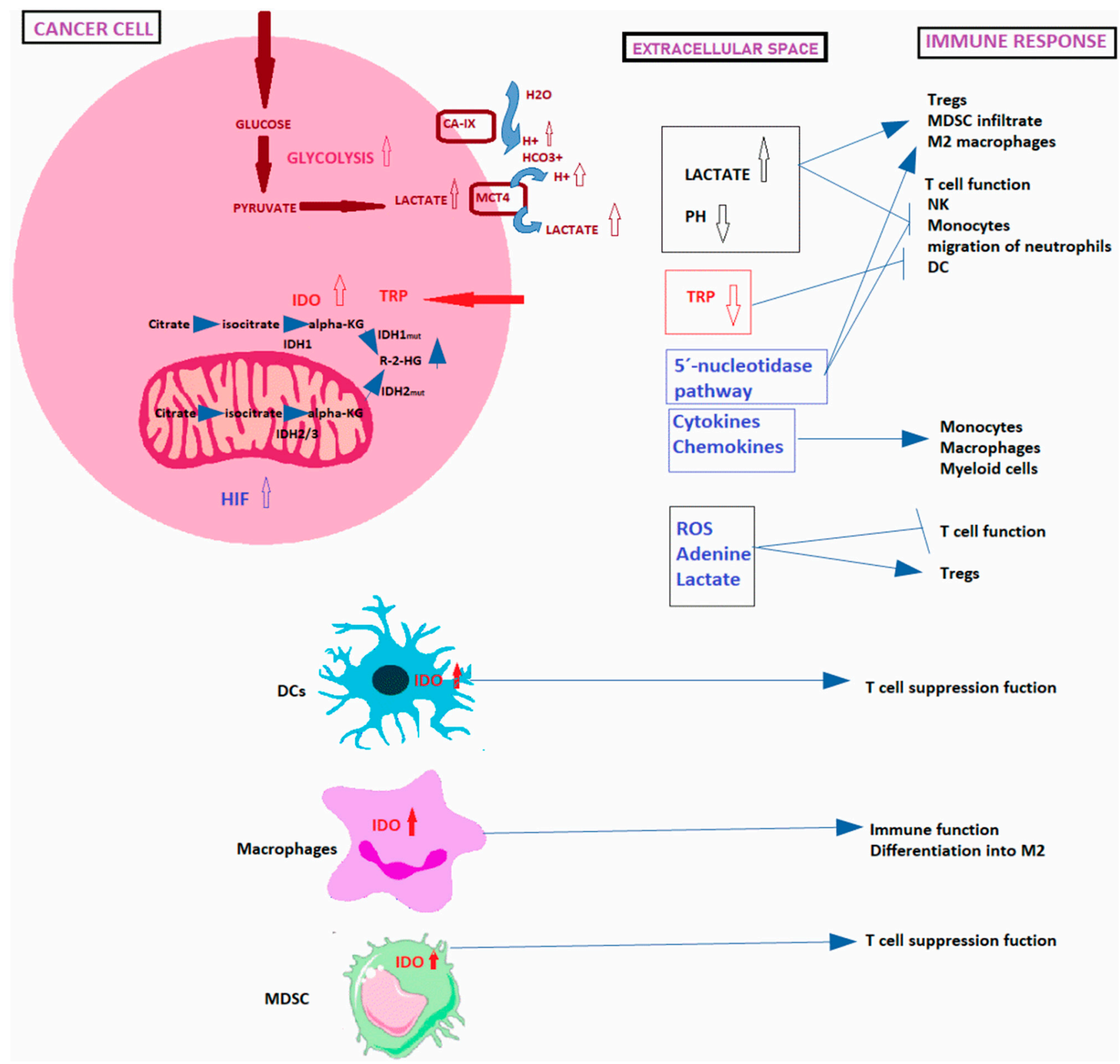

Figure 3. Mechanisms of immunosurveillance scape. Including lactate and proton release by cancer cells within the TME and the consecutive immune response, consequences of indoleamine 2,3 dioxygenase (IDO) overexpression and hypoxia and hypoxia inducible factor (HIF) production by cancer cells on the antitumoral immune response, and lastly Isocitrate dehydrogenase (IDH) mutations in cancer cells, promoting the accumulation of R-2-HG oncometabolite. Dendritic cells (DCs), tryptophan (TRP), myeloid-derived suppressor cells (MDSC); Reactive Oxygen Species (ROS); natural killer cells (NK); dendritic cells (DC), regulatory T cells (Tregs).

In cancer cells, hypoxia triggers a metabolic shift towards glycolysis since the absence of oxygen limits the use of OXPHOS [34]. Hypoxia conditions also induce the overexpression of several glycolytic enzymes through Akt activation [35]. Hypoxia inducible factor Alpha (HIF-1 $\alpha$ ) transcription factor targets genes that constitute an adaptation for metabolic rewiring. These include vascular endothelial growth factor (VEGF) and its receptors to regulate vascular remodeling and plasticity, enzymes of the glycolytic pathway (i.e., hexokinase 2, lactate dehydrogenase) and glucose transporters, as well as Carbonic Anhydrase IX (CA-IX) for $\mathrm{pH}$ regulation [36]. 


\subsubsection{Acidification of the TME}

As per the Warburg effect, cancer cells produce significant amounts of lactate that accumulates in the TME. Lactate is exported by co-transport with protons through the Mono-Carboxylate Transporters (MCTs) and promotes acidification within the TME. Additionally, acidification can be potentiated by membrane CA-IX upregulated by the HIF pathway. CA IX promotes acidification in the TME since its active site faces the extracellular space and catalyzes $\mathrm{CO}_{2}$ hydration, which produces protons outside of the cancer cells. CA IX also cooperates with bicarbonate transporters, as well as MCTs, to transport acid from the intracellular space of the cancer cells to the TME [37]. The proteoglycan-like domain of CA IX mediates non-catalytic export of protons coupled with export of lactate in cancer cells through MCT [38].

Acidification of the TME provides a growth advantage to tumor cells at the expense of immune cells, as it inhibits proliferation and function of $\mathrm{T}$ cells, affects the function of monocytes and NK cells, and acts over the chemotaxis and migration of neutrophils and DCs while promote Treg formation, myeloid-derived suppressor cells (MDSCs) and M2 polarized macrophages infiltration with greater immunosuppressive effects on T cells [30] (Figure 3).

\subsubsection{Role of Amino Acids in Battle between Immune and Cancer Cells}

Changes that disrupt the amino acids metabolism and availability in the TME constitute important targets for cancer cells to circumvent the immune response since immune cell correct functioning requires homeostasis of the amino acid metabolism. For example, Indoleamine 2,3-Dioxygenase (IDO) expression can be induced by Interferon-gamma (IFN $\gamma$ ) or can be constitutively overexpressed by mutations in BIN and KIT oncogenes [27]. IDO regulates the tumor functions associated with inflammation and its overexpression leads to tryptophan deprivation, which suppresses CD8+ T effector cells and NK cells while inducing Tregs and MDSC, impairing immune cell functions (Figure 3) [27]. Furthermore, overexpression of glutaminase leads not only to depletion of glutamine levels but also to high glutamate levels that might impair the immune function [28]. Cysteine is necessary for glutathione synthesis, ROS detoxification, and T-cell activation [39] (Siska et al. 2016). Thus, inhibition of cysteine uptake impairs T-cell activation, as it is critical for the Reactive Oxygen Species (ROS) detoxification machinery [28].

\subsubsection{Hypoxia}

Hypoxia is a common feature of tumor tissues that arises because of oxygen diffusion limitations and an abnormal vasculature. Response to hypoxia is mediated by HIF- $1 \alpha$ transcription factor which is commonly overexpressed in tumors [40]. HIF- $1 \alpha$ can be activated by growth-signaling pathways, such as PI3K/Akt/mTOR or MAPK [41], and some oncometabolites, such as fumarate and succinate, can also induce HIF-1 $\alpha$ signaling [42].

HIF- $1 \alpha$ promotes the expression of several cytokines and chemokines that attract monocytes, macrophages and myeloid cells [43]. Monocytes differentiate into tumorassociated macrophages (TAMs) whose infiltration is closely related to tumor cell proliferation as they impair T-cell proliferation and cytotoxic activities, trigger inflammation and promote cancer; meanwhile, myeloid cells, such MDSCs, contribute to immunosuppression [44]. $\mathrm{O}_{2}$-deprived cancer cells may also release ROS and metabolites, such as adenine and lactate, that inhibit T-cell function and recruit Tregs with immunosuppressive functions [28]. The 5'-nucleotidase pathway is induced by hypoxia leading to adenosine accumulation in tumors impairing the immune function (T cells, NK and activation of immunoregulatory M2) [28].

Together with HIF-1 $\alpha$ (HIF1A), at least five additional members of the HIF family: HIF$1 \beta$ (ARTN), HIF-2 $\alpha$ (EPAS1), HIF-2 $\beta$ (ARNT2), HIF-3 $\alpha$ (HIF3A), have been discovered in human. HIF- $1 \beta$ is a dimerization partner of HIF- $1 \alpha$ for the hypoxia signaling that together with HIF- $1 \alpha$ form the transcriptional active complex HIF-1. HIF-1 $\beta$ is constitutively expressed and unaffected by hypoxia. However, certain tumor cell lines derived from 
different entities are capable to elevate HIF-1 $\beta$ expression under hypoxic conditions which implies a survival benefit. It has been demonstrated that HIF-1 $\beta$ is a potential direct target gene of HIF-1 in human Hep3B hepatocellular carcinoma cells [45]. In the case of HIF-2 $\alpha$, it has been found that is involved in the extracellular ATP promotion of breast cancer invasion and epithelial-mesenchymal transition [46]. Overexpression of HIF-2 $\beta$ is associated with decreased cell proliferation and better prognosis in gastric cancer [47], whereas HIF-3 $\alpha$ is a potent prognostic biomarker in different kinds of cancer [48].

\subsubsection{Signaling Events Induced by Metabolite-Sensing}

Cells need to perceive the changes in intracellular and extracellular metabolites to interact with the environment and respond accordingly. Therefore, in addition to their role in biosynthesis, metabolites also modulate protein activity, cell signaling, and gene expression. Thus, metabolic signals contribute to immune cell function and impact anticancer immunity so they can be modulated to optimize cancer [49]. AMP-activated protein kinase (AMPK) and mTOR signaling are master regulators of cell metabolism and constitute good examples of the signaling pathways induced by metabolic-sensing. AMPK is a sensor of cellular energy and nutritional status; therefore, it plays a key role in the regulation of the cell energy homeostasis and carcinogenesis as energy balance dysregulation is an important driver of the alterations in cancer [50]. Changes in AMP/ATP ratio regulate the activity of key metabolic enzymes governing anabolic and catabolic pathways that facilitate cell survival, control mitochondrial respiration, nutrient transport, autophagy, differentiation, and cell polarity [51]. An increased ratio of AMP/ATP in metabolically stressed cells enhances phosphorylation of AMPK that results in activation of ATP- producing pathways [21]. Moreover, mTORC1-mediates the amino acid sensing with the help of arginine sensor proteins and the arginine level controls mTOR activity [50]. In cancer cells dysregulation of the PI3K/Akt or the Ras/ERK signaling are coupled to mTOR activation which controls differentiation, proliferation, survival, cytoskeleton organization and autophagy [51]. Other examples of metabolite sensors constitute transmembrane proteins, such as G-protein-coupled receptors, that can function as a succinate and $\alpha$-ketoglutarate receptor that sense metabolites for the TCA cycle [50] which importance in oncogenesis relays in the control of cellular energy and synthesis of precursors for biosynthetic pathways [52]. Metabolic signals contribute to immune cell function and impact anticancer immunity, so that they can be modulated to optimize cancer immunotherapy. New cancer therapies can be found by better understanding the nutrient-sensing processes in T cells, since it will allow us to enhance their metabolic capability to compete for nutrients with cancer cells. Immunometabolic signaling is dynamically regulated through the interplay of nutrient signaling networks and serine/threonine kinases, such as the PI3K-AGC kinases, mTOR and LKB1-AMPK pathways [48]. Changes such as activation of AMPK or inhibition of mTOR promote Tregs over TEFFs and inhibit the function of NK cells [53]. Phospholipids can also be key second messengers that are highly regulated regarding to turnover, since they influence downstream immunometabolic pathways; for example, PI3K activity induces diverse signaling pathways involved in regulating cellular function, including Akt, phosphoinositide-dependent protein kinase 1 and mTOR. Lipid molecules such as cholesterol and FAs play a key role in the activation, differentiation, and function of T cells [54] (Wei et al. 2017). PI3K also controls lipid and cholesterol content which are integral components of cellular membranes and is also an important regulator of autophagy essential for T-cell homeostasis, function and differentiation [49] (Saravia et al. 2020).

Glucose sensing regulates and shapes T-cell responses as glucose transporting GLUT1 expression and glycolysis promote TEFF cell and Treg cell proliferation impair Treg cell lineage stability and suppressive function [54] (Wei et al. 2017). T and tumor cells reprogram their metabolism to enhance glucose uptake and aerobic glycolysis to compete for glucose in the TME and in the glucose-limited TME, the immune response of tumor-infiltrating $\mathrm{T}$ cells is less effective than in T cells from glucose-rich environments [54]. Activated T cells have a glucose-sensitive metabolic checkpoint controlled by AMPK, which regulates 
mRNA translation and glutamine-dependent mitochondrial metabolism needed to sustain T-cell metabolic homeostasis mediating adaptive immunity [55].

Numerous studies have demonstrated that drugs that inhibit the mechanistic target of rapamycin (mTOR) and activate AMP-kinase (AMPK) have beneficial effects in promoting differentiation and blocking proliferation of different cancers, i.e., in hematological malignancies such as acute myeloid leukemia (AML) [56]. In solid cancers such as glioma, agents such as isogambogenic acid [57] and compound C [58] inhibit glioma growth through the activation of the AMPK-mTOR pathway. In pancreatic cancer, repurposing of metformin and aspirin by targeting AMPK-mTOR and inflammation is used for prevention and treatment [59]. In prostate cancer it has been found that small-molecule natural inhibitors of the PI3K/Akt/mTOR Pathway can be useful for chemoprevention and intervention [60]. In breast cancer, AMPK activators suppress breast-cancer-cell growth by inhibiting DVL3facilitated Wnt/y can be useful for chemn by targetin [61]. In non-small-cell lung cancer (NSCLC) heat treatment led to the increased phosphorylation of AMPK and the decreased phosphorylation of mTOR in vitro and in vivo. Moreover, in NSCLC, the GRP78 knockdown inhibits the AMPK-mTOR pathway, and the AMPK inhibitor compound C decreased heat-induced autophagy, suggesting that activation of ER stress was involved in autophagy induction and promotion of the AMPK-mTOR pathway [62].

\subsubsection{Macromolecules and Organelles Released in the TME}

Macromolecules and organelles released by noncancerous cells in the TME support biosynthetic and bioenergetic needs of the cancer cells and due to the overlapping metabolic demands of cancer and immune cells in the tumor ecosystem, the transfer of this metabolic resource confer cancer cells with a growth advantage over immune cells [63]. Intercellular organelle transfer has been demonstrated to be an important survival mechanism under external stress conditions [63]. Being either unidirectional or bidirectional, intercellular organelle transfer is a process in which whole organelles are donated from one cell to another with the transfer of cytosol and plasma membrane components, as well as of small molecules and ions by ATP-dependent mechanisms through nanotubes. In this process, the endoplasmic reticulum/Golgi bodies, endosomes, lysosomes and mitochondria originating in one cell (organelle donor) are transported to another cell [63]. Mitochondrial transfer phenomenon is involved in cancer progression by modulating inflammation processes, chemotherapy resistance and, thus, cancer cell survival, and it can be advantageous for the survival of cancer cells that have fully functioning mitochondria [64].

\subsubsection{Reverse Warburg Effect}

The novel concepts of the "reverse Warburg effect" and the "autophagic tumor stroma model of cancer metabolism" are supported by the evidence that enhanced aerobic glycolysis and/or autophagy in the cancer-associated fibroblasts (CAFs) sustains epithelial cancer cell growth via the secretion and transfer of high-energy metabolites by the tumor stroma including ketones, lactate, amino acids (glutamine) and nucleotides [65]. Additionally, CAFs contribute to a strong immunosuppressive effect having lactic acidosis in the TME [66] and CAF-derived exosomes have also been shown to contain nutrients $[65,67]$.

\subsection{Crosstalk between the TME, Extracellular Matrix and Cell Metabolism in Cancer}

Cancer cells interact with both the immune system and the stroma, while fibroblasts, and other stromal cells, can interact with immune system and influence its response. A deep comprehension of the dynamic interactions between cancer stromal and immune cells in the TME ecosystem is required to predict the resulting pro- or antitumor effects [2]. The extracellular matrix (ECM) is a complex network of secreted proteins that creates a complex 3D microenvironment providing mechanic support for tissues and organs while controlling many cell functions, including cell polarity, migration, proliferation, oncogenic transformation, metabolic plasticity and responsiveness to therapies targeting cell metabolism [68]. CAFs and cell-ECM interactions are key elements in controlling these 
metabolic changes. CAFs and other stromal cells can recruit immune cells to the tumor [2] and CAFs undergo the reverse Warburg effect providing cancer cells with glycolytic metabolites that help cancer cells support the Warburg effect [69]. ECM components, such as fibronectin and laminin, are internalized by integrins and control nutrient signaling pathways in a reversible control manner which affects the ability of cancer cells to grow under nutrient deprived conditions and this way have a metabolic advantage over the immune cells [70].

\section{Genome Scale Metabolic Modeling in Cancer}

\subsection{GEMs}

GEMs are mathematical representations of the metabolic potential of an organism; they define the whole set of stoichiometry-based, mass-balanced metabolic reactions in an organism. To date, a number of generic GEMs of human metabolism have been reconstructed, including Human Metabolic Reaction (HMR) series: HMR [71] and HMR2 [72]; The Recon series: Recon 1 [73]; Recon 2 [74] and Recon3D [75]; and the Edinburgh model [76] and they have been extensively used in the study of cancer metabolism (Table 1). A key component of GEMs is the biomass function, an artificial reaction that serves as a surrogate for the metabolic demand (i.e., building blocks, metabolic energy and reductive power) required for growth and proliferation. A second feature of GEMs are Gene-Protein-Reaction (GPR) annotations, a set of rules that define the isoenzymes or protein complexes that catalyze each reaction, enabling to map transcriptomics and proteomics measures to GEM reactions [77-80].

Table 1. Human metabolic generic models and their complexity in terms of number of genes, reactions and metabolites.

Adapted from [79].

\begin{tabular}{|c|c|c|c|c|c|}
\hline Human Generic Model & No. of Genes & $\begin{array}{c}\text { No. of } \\
\text { Reactions }\end{array}$ & $\begin{array}{c}\text { No. of } \\
\text { Metabolites }\end{array}$ & $\begin{array}{l}\text { Cancer-Type } \\
\text { Application }\end{array}$ & $\begin{array}{l}\text { Application } \\
\text { References }\end{array}$ \\
\hline Human Metabolic Reaction (HMR) [71] & 3668 & 8100 & 6000 & Renal carcinoma & [81] \\
\hline $\begin{array}{l}\text { Human Metabolic Reaction (HMR2) } \\
\text { [72] }\end{array}$ & 3765 & 8181 & 6007 & $\begin{array}{l}\text { Hepatocellular } \\
\text { carcinoma }\end{array}$ & [82] \\
\hline \multirow{3}{*}{ Recon 1 [73] } & \multirow{3}{*}{1496} & \multirow{3}{*}{3311} & \multirow{3}{*}{2766} & Generic cancer & [83-85] \\
\hline & & & & 16 cancer types & [82] \\
\hline & & & & NCI-60 CCLs & [86] \\
\hline Recon 2 [74] & 1789 & 7440 & 2626 & $\begin{array}{l}9 \text { cancer types from } \\
\text { TCGA }\end{array}$ & [87] \\
\hline Recon 3D [75] & 3288 & 13,543 & 4140 & Prostate cancer & {$[80]$} \\
\hline Edinburgh model [76] & 2322 & 2823 & 2671 & Colon and breast CCLs & [88] \\
\hline
\end{tabular}

Abbreviations: (CCL) cancer cell line.

\subsection{Constraint-Based Modeling}

The analysis of the distinct usage of metabolic pathways in cancer metabolism requires the quantification of metabolic fluxes. A metabolic flux is the rate at which substrates are converted to products through a given reaction or pathway. Constraint-based modeling, sometimes referred to as stoichiometric modeling, is a modeling approach that uses a set of linear constraints to simulate steady-state metabolic fluxes across a metabolic network. This approach assumes a metabolic quasi-steady state where no intracellular metabolites accumulate or deplete, as their average concentration can be assumed constant in time. This assumption is generally valid for intracellular metabolites as they transition towards a quasi-steady state several orders of magnitude faster than variations in extracellular metabolite concentrations or the gene-expression program of the cell [89]. Since intracellular concentrations are assumed constant under quasi-steady state, the input and output fluxes for each metabolite must be balanced. In constraint based-modeling, this constraint is 
written as $S \times v=0$, where $S$ is the stoichiometric matrix, which defines the stoichiometric coefficients of each metabolite in each of the reactions in the network, and $v$ is the vector of steady state fluxes (Figure 4A). Additionally, flux boundaries can be set to satisfy thermodynamic laws (i.e., reaction reversibility) or with measured rates of metabolite uptake and secretion (Figure 4D). Since constraint-based modeling relies primarily on network stoichiometry, which is well-defined on a GEM and does not require precise knowledge of the kinetic properties of enzymes, it is widely used to model metabolic fluxes in GEMs [77-79,90].

A

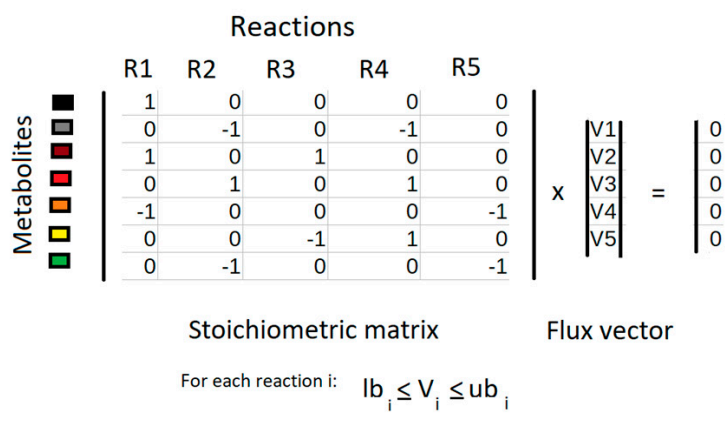

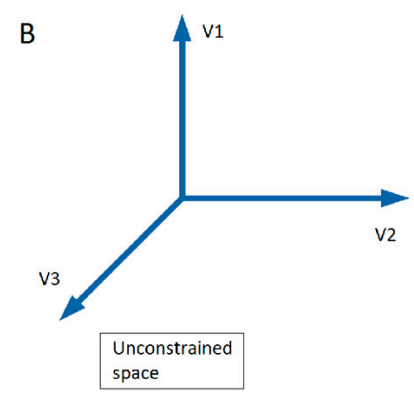
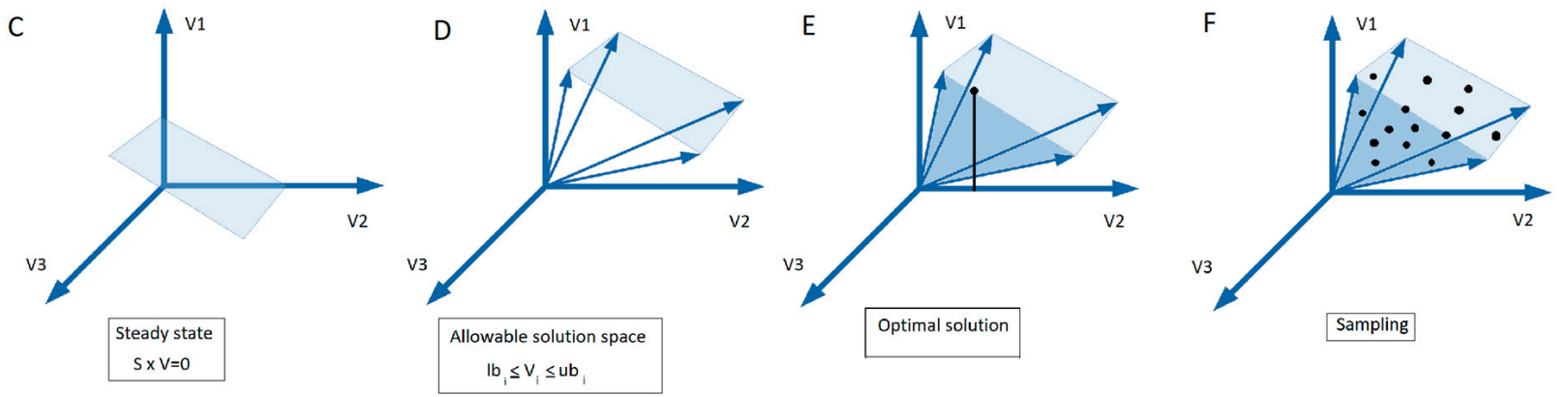

Figure 4. Genome-scale metabolic modeling. (A) FBA optimization maximizes a linear objective function, $\psi(v)$, formed by the dot product of the flux vector containing each reaction flux, $\left(v_{i}\right)$ by a predetermined coefficient, $c_{i}$, in the stoichiometric matrix $(S)$ subject to a steady-state assumption, $S v=0$, as well as lower and upper bounds on each reaction flux $\left(l b_{i}\right.$ and $\left.u b_{i}\right)$. From the unconstrained space (B), the allowable solution space is defined by specifying the steady-state assumption (C), as well as lower and upper bounds on each reaction flux (D). Various methods can then be used to interrogate the solution space, such as (E) optimization for a biologically motivated objective function to identify a single optimal solution (e.g., flux vector in case FBA optimization method is used) or (F) sampling to provide an unbiased characterization via flux vectors uniformly distributed in the solution space.

However, the space of solutions emerging from the abovementioned constraints in a GEM is generally largely undetermined (Figure 4B) (i.e., there is a wide range of possible flux distributions, many of them biologically irrelevant). To overcome this limitation, Flux Balance Analysis (FBA) identifies the optimal flux distribution(s) by maximizing a biologically motivated objective function, such as the flux, through the biomass reaction (Figure 4E) [91]. Nevertheless, there can still potentially be multiple flux distributions that maximize a given objective. Phenotypically different alternate optimal solutions can yield the same optimal objective value resulting from a FBA optimization. The range of optimal flux distributions can be estimated by Flux Variability Analysis (FVA). FVA estimates the allowable range of flux values through a given reaction by finding the maximum and minimum possible fluxes from the several solutions that satisfy the optimal objective function's value, such as maximum biomass production, called the alternate optimal solution space [92]. Therefore, alternate optimal solution space can be quantified by using FVA, since it provides a range of minimum and maximum values for each reaction of the system [92]. 
An alternative to these methods consists of using sampling methods that avoid the need to specify an objective function by estimating the distribution of possible flux values in the solution space through techniques such as Uniform Random Sampling and Hit-andRun Sampling [93-96]. The solution space can then be characterized statistically from the set of sampled flux vectors in terms of a probability density function (Figure 4F). Uniform Random Sampling obtains a statistically meaningful number of solutions uniformly distributed through the entire solution space. Hit-and-Run Sampling is a Markov chain Monte Carlo method in which the solution space is randomly sampled [97].

Given that the solution space is often underdetermined, recent studies have enabled the incorporation of thermodynamics constraints and integrated metabolomics data to ensure that the simulated flux maps are thermodynamically and kinetically feasible. For example, anNET, by testing the thermodynamic consistency of the data by identifying thermodynamically infeasible errors and by predicting the concentrations beyond the quantitative data being measured, makes a quality check of metabolite concentrations and enables to identify the reactions whose metabolic flux is actively regulated [98]. Thermodynamicsbased Flux Analysis (TFA) integrates quantitative metabolomics data and standard Gibbs free energy release of reactions [99] to add a thermodynamic constraint to each reaction that ensures that the directionality of each reaction is feasible given the ratio of concentrations between substrates and products [100]. While pyTFA and matTFA were the first implementations of the TFA [101], a modified version of matTFA that considers alternative parameter values and methods has been developed in by Tomi-Andrino et al. [102], and recently, mod-matTFA toolbox was implemented.

TC-iReMet2 is a constraint-based modeling approach to account for magnitude of flux changes that combines relative metabolite and transcript time-course data to estimate fluxes, providing a more accurate explanation of flux rerouting over time [103]. Linear Bound Flux Balance Analysis (LBFBA) uses transcriptomic or proteomic expression data and adds on individual fluxes soft constraints whose parameters are estimated from a training expression and flux dataset that are then used to predict metabolic fluxes from expression data in other conditions [104]. Relative Expression and Metabolomic Integration (REMI) uses GEMs to translate differential gene expression and metabolite abundance data into differential fluxes to analyze the dysregulated physiology for any given pair of conditions by integrating differential gene expression and differential metabolite abundances with thermodynamic data into a single framework, and then maximizing the consistency between them [105].

\subsection{Context-Specific GEMs}

At a given cell or tissue, only a subset of enzymes is expressed; thus, it is generally recommended to integrate transcriptomics, proteomics or other condition-specific data to generic GEMs of human metabolism to build context-specific GEMs. A context-specific GEM is a subset of the generic GEM in which inactive reactions are removed to reflect cell-type- or tissue-specific metabolic phenotypes. This contextualization process (Figure 5) depends on: generic GEM chosen, definition of the biomass function, uptake and secretion flux constraints, gene expression levels, metabolomics, and tissue- or cell-specific metabolic functions of the cell or tissue type that need to be active in the extracted model. Additionally, the algorithm and parameter selection (e.g., gene expression thresholds and metabolic constraints) can affect model content and predictive accuracy. Thus, context-specific modeling often requires evaluation procedures for the selection of such parameters [106]. Model extraction methods (MEMs) are omics data-integration algorithms used to create context-specific GEMs. MEMs include GIM³ E [107], iMAT [108], MBA [109], INIT [82], mCADRE [110], tINIT [82], CORDA [111], FastCore [112] and FASTCORMICS [113]. In all of these methods there are two critical points: (1) the gene expression pre-processing controlling the distinction between active and inactive genes and (2) Gene to reaction mapping by GPR associated with each reaction. 
Context-specific GEMs have a wide range of applications, such as identifying putative drug targets [114], predicting of host-pathogen metabolic interactions [115,116] or characterizing the reprogrammed metabolism of liver cancer stem cells [117]. Some databases with published context-specific GEMs include the BioModels Database [118] (https:/ / www.ebi.ac.uk/biomodels-main/ [Accessed on 1 January 2020]), metabolic atlas [119] (https://www.metabolicatlas.org/ [Accessed on 1 January 2020]) and BIGG models database [120] (http:/ /bigg.ucsd.edu/ [Accessed on 1 January 2020]).

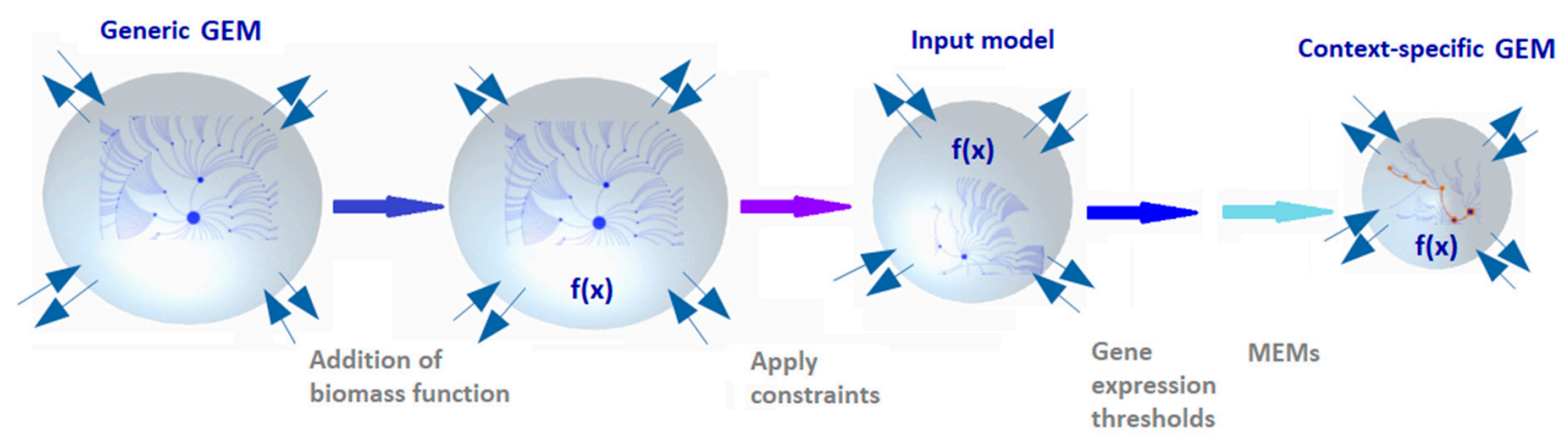

Figure 5. Overview of key steps in the constraint-based modeling process. Extracting a context-specific model representing the metabolism of a tissue type or cell line requires several steps. The most salient steps consist of choosing the kind of generic model to use, the addition of the biomass function, how to constrain the uptake and secretion fluxes in the model, defining of the gene expression threshold to include a gene in a reaction and choosing the MEM algorithm to use for extraction.

\subsection{Kinetic Models}

Constraint-based approaches make use of network stoichiometry to characterize the intracellular fluxes at steady state and cannot generally simulate fluxes and metabolite concentrations outside of the quasi-steady state nor simulate the regulatory loops emerging from the kinetic properties of enzymes. Kinetic models use mathematical expressions referred to as kinetic laws or rate equations which compute the rate through an enzymecatalyzed reaction as a function of metabolite and enzyme concentrations and the kinetic parameters of the enzymes. Substituting the rate equations in the mass balance equation $(S \times v)$ results in a system of ordinary differential equations (ODEs) describing the metabolite concentration changes over time. The equations for the reaction rates are functions of enzyme concentrations, kinetic parameters and metabolite concentrations, so it is possible to describe the stoichiometric relation between substrate and products considering the enzymatic mechanisms and different levels of regulation (i.e., allosteric or post-transcriptional regulation), making these methods appropriate for multiple omics data types' integration. Therefore, solving such models enables dynamic analysis of biological systems and allows quantitative predictions of the cells' states along time for enhanced in silico hypothesis generation. Kinetic models have been typically used to generate efficient strain optimization algorithms [121], although they have also been extensively applied to model cancer metabolism [122-124].

Kinetic models are typically built in a bottom-up manner: for each reaction, a kinetic law with its respective parameter values should be provided, resulting in model structures with great amounts of parameters. The model parameters can be experimentally assessed through the literature, experimental measures or databases, such as Brenda [125] or SABIORK [126]. Alternatively, model parameters or parameter uncertainty can be estimated by using parametric estimation methods [127,128] or Monte Carlo methods [129,130].

Kinetic models have to be compatible with physicochemical laws, such as electroneutrality and osmotic balance, experimental flux and metabolite measurements to reduce model uncertainty and discard the reaction directionalities that are not consistent with the observed physiology [131]. Kinetic rate laws should also be able to model enzyme saturation and the mechanistic regulatory details [131]. 
Because of this complexity, kinetic models are often of limited scope, covering one or a few metabolic pathways, but the network of metabolism is highly interconnected and the dynamics of the whole system are required to simulate its behavior. Recent efforts have been made towards building genome-scale kinetic models [132-135].

Alternatively, it is possible to reduce the model complexity by modeling in detail only the kinetics of reactions that are important for a particular physiological condition and for the remaining reactions use simple approximate kinetic laws, such as considering a quasisteady state, and then modeling these parts by stoichiometry only. Ensemble modeling wherein multiple models are combined in order to create a feasible solution space constitutes a solution to address kinetic parameter scarcity and small-scale preference [136,137]. ORACLE [138], GRASP [139] and K-FIT [140] are packages for ensemble modeling.

\subsection{Application of Metabolic Analysis Tools in Cancer Research}

\subsubsection{Software for Constraint-Based Modeling Tools}

One of the most widely used frameworks for constraint-based modeling is the family of Constraint-Based Reconstruction and Analysis (COBRA) packages. Available in MATLAB [141], Python [142] and Julia [143], this family of open-source packages provide community-contributed modules to perform a variety of constraint-based modeling analysis, including FBA, FVA, flux sampling, in silico gene Knockouts (KOs) and a variety of MEMs algorithms that allow network integration of metabolomics, transcriptomics, proteomics and thermodynamic data. The MEM data integration is used to simulate different metabolic phenotypes, including growth rate and gene essentiality. Essential and synthetic lethal genes are defined by using in silico $\mathrm{KO}$ strategies that disrupt the biomass reaction's flux by blocking the biosynthesis of at least one essential metabolite and halt cellular proliferation. Other frameworks for constraint-based modeling and/or GEM metabolic reconstruction are reviewed in detail in $[141,144]$ (Table 2).

Table 2. Software applications for constraint-based modeling and/or genome-scale metabolic reconstruction. In References [141,144], all of these tools are reviewed in more detail.

\begin{tabular}{|c|c|c|c|c|}
\hline Name (and Reference) & Language & Interface & Development & OS \\
\hline COBRA Toolbox [141] & $\begin{array}{c}\text { MATLAB } \\
\text { COBRA.py, COBRA.jl (Python and Julia) }\end{array}$ & Script & Open source & $\mathrm{All}^{\mathrm{M}}$ \\
\hline RAVEN [145] & MATLAB & Script & Open source & $\mathrm{All}^{\mathrm{M}}$ \\
\hline CellNetAnalyzer [146] & MATLAB & Script/GUI & Closed source & $\mathrm{All}^{\mathrm{M}}$ \\
\hline FBA-SimVis [147] & MATLAB/Java & GUI & Closed source & Windows \\
\hline OptFlux [148] & Java & Script & Open source & All \\
\hline Sybil [149] & $\mathrm{R}$ & Script & Open source & All \\
\hline CBMPy [150] & Python & Script & Open source & All \\
\hline SurreyFBA [151] & $\mathrm{C}++$ & Script/GUI & Open source & All \\
\hline FASIMU [152] & $\mathrm{C}$ & Script & Open source & Linux \\
\hline FAME [153] & Web-based & GUI & Open source & All \\
\hline PathwayTools [154] & Web-based & GUI/script & Closed source & All \\
\hline Kbase [155] & Web-based & Script & Open source & All \\
\hline AutoKEEGRec [156] & MATLAB & Script & Open source & $\mathrm{All}^{\mathrm{M}}$ \\
\hline AuReMe [157] & Python & GUI & Open source & All \\
\hline CarveMe [158] & Python & Script & & \\
\hline MetaDraft [159] & Python & Script & Open source & All \\
\hline ModelSEED [160] & Web-based & GUI & Open source & All \\
\hline
\end{tabular}


Table 2. Cont.

\begin{tabular}{ccccc}
\hline Name (and Reference) & Language & Interface & Development & OS \\
\hline PathwayTools [161] & Common Lisp & GUI (API) & Open source & All \\
\hline Merlin [162] & Java & GUI & Open source \\
\hline CoReCO [163] & Python & Script & Open source & All \\
\hline MEMOSys [164] & Java & GUI & Proprietary source & All \\
\hline GEMSiRV [165] & Java & GUI & Open source & All \\
\hline MetExplore [166] & Web-based & GUI & Open source & All \\
\hline RbioNet [167] & Part of the COBRA ToolBox & Script & Open source \\
\hline MetaFlux [168] & Web-based & GUI & Open source (distributed & as part of Pathways tools)
\end{tabular}

Abbreviations: $\left(\mathrm{All}{ }^{\mathrm{M}}\right)$ all operative systems in which it can run MATLAB, (API) Application Programming Interface, (GUI) Graphic User Interface, (OS) operative system.

\subsubsection{Application of GEMs in Metabolic Cancer Research}

GEMs have been widely used to analyze the metabolic phenotype underlying cancer, find cancer-specific metabolic essential genes that are putative novel drug targets in cancer and stratify patients [169]. Table 3 describes a number applications of GEMs in cancer research, such as modeling of the Warburg effect; predicting potential biomarkers, drug targets and adverse drug effects; identifying metabolic signatures for drug repositioning; and determining and identifying anti-metabolites for metabolic inhibitors to co-administrate in adaptive therapies.

Table 3. Application of GEMs in metabolic cancer research.

\begin{tabular}{|c|c|c|c|c|c|}
\hline Reference & Category & Concept & Tools Used & Databases & Type of Validation \\
\hline [170] & $\begin{array}{l}\text { CSGEMs to } \\
\text { generate metabolic } \\
\text { signatures for drug } \\
\text { repositioning }\end{array}$ & $\begin{array}{l}\text { PC GEM to explore PC metabolism and } \\
\text { repurpose new drugs. Reconstruction } \\
\text { performed combining personalized GEMs } \\
\text { from individual patient's transcriptome and } \\
\text { PC-specific proteomics data from the HCA. }\end{array}$ & $\begin{array}{l}\text { RAVEN, } \\
\text { FastGeneSL } \\
\text { [171], DIRAC, } \\
\text { TCGAbiolinks, } \\
\text { DESeq, gcrma }\end{array}$ & $\begin{array}{l}\text { HPA, HMA, } \\
\text { Connectivi- } \\
\text { tyMap2 }\end{array}$ & $\begin{array}{c}\text { In silico cell viability } \\
\text { assay and in vitro cell } \\
\text { assay. }\end{array}$ \\
\hline [172] & $\begin{array}{l}\text { CSGEMs to predict } \\
\text { biomarkers and } \\
\text { drug targets }\end{array}$ & $\begin{array}{l}\text { GEM of transcriptional regulator-metabolite } \\
\text { associations with mixed computational and } \\
\text { wet lab experiments integrating intracellular } \\
\text { metabolic profiles of NCI- } 60 \text { (4) } 54 \text { CCLs with } \\
\text { transcriptomic and proteomic data. Perform } \\
\text { metabolic profiling of CCLs and resolve } \\
\text { signaling across multiple regulatory layers. }\end{array}$ & $\begin{array}{l}\text { fitlm (Matlab) } \\
\text { sparseNCA }\end{array}$ & $\begin{array}{l}\text { Gene } \\
\text { Expression } \\
\text { Omnibus } \\
\text { NCI-60, } \\
\text { HMD, } \\
\text { TRRUST, } \\
\text { KEGG }\end{array}$ & $\begin{array}{l}\text { In vivo metabolite } \\
\text { fold-changes between } \\
\text { normal and cancer } \\
\text { tissues. }\end{array}$ \\
\hline [83] & $\begin{array}{l}\text { CSGEMs to predict } \\
\text { biomarkers and } \\
\text { drug targets }\end{array}$ & $\begin{array}{l}\text { CSGEM to study the role of metabolic } \\
\text { alterations for novel therapy targets. Predicts } \\
52 \text { cytostatic drug targets }(40 \% \text { by known } \\
\text { drugs). Analyze synthetic lethal drug targets } \\
\text { to identify drug synergies. }\end{array}$ & & NCI-60 & $\begin{array}{l}\text { shRNA data, cytostatic } \\
\text { scores for single and } \\
\text { double drug target } \\
\text { predictions, synergistic } \\
\text { drug targets via yeast } \\
\text { orthologs. }\end{array}$ \\
\hline [173] & $\begin{array}{l}\text { GEMs to identify } \\
\text { antimetabolites for } \\
\text { drug design }\end{array}$ & $\begin{array}{l}\text { Assess anticancer effects of drugs structurally } \\
\text { similar to DrugBank [174]. Uses Tanimoto } \\
\text { scores from OpenBabel [175] to assess } \\
\text { structural similarity between DrugBank drugs } \\
\text { and metabolites CSGEM predicted to be } \\
\text { essential for maximal growth rate. Developed } \\
\text { pyTARG to constrain the HMR, using } 34 \text { CCLs } \\
\text { and } 26 \text { healthy tissue RNA-Seqs. Implemented } \\
\text { FBA within PyTARG to quantify the original } \\
\text { drug affecting reactions rates decrease. Model } \\
\text { the impact of a relative inhibition on global } \\
\text { cell metabolism. }\end{array}$ & $\begin{array}{c}\text { OpenBabel [175], } \\
\text { pyTARG, } \\
\text { COBRApy }\end{array}$ & $\begin{array}{l}\text { DrugBank } \\
\text { [174], KEGG, } \\
\text { BioProject, } \\
\text { HPA, GEO, } \\
\text { BioModels }\end{array}$ & $\begin{array}{l}\text { Differential effects of a } \\
\text { lipoamide analog on } \\
\text { MCF7 and ASM cells. } \\
\text { Proof of concept of } \\
\text { identification of } \\
\text { therapeutic windows. }\end{array}$ \\
\hline
\end{tabular}


Table 3. Cont.

\begin{tabular}{|c|c|c|c|c|c|}
\hline Reference & Category & Concept & Tools Used & Databases & Type of Validation \\
\hline [109] & $\begin{array}{c}\text { GEMs to identify } \\
\text { antimetabolites for } \\
\text { drug design }\end{array}$ & $\begin{array}{c}\text { Proteomics samples from } 27 \text { HCC patients and } \\
83 \text { healthy individuals from HPA to } \\
\text { reconstruct cancer and healthy GEMs with the } \\
\text { tINIT from the HMR } 2.0 \text { generic GEM. } \\
\text { CSGEMs to identify antimetabolites used as } \\
\text { anticancer drugs. Healthy GEMs to explore } \\
\text { candidate antimetabolites toxicity on healthy } \\
\text { samples. }\end{array}$ & $\begin{array}{c}\text { RAVEN } \\
\text { (gap-filling, } \\
\text { tINIT, } \\
\text { checkTasks) }\end{array}$ & HPA & $\begin{array}{c}\text { Usage of } \\
\text { antimetabolites for } \\
\text { treatment of HCC } \\
\text { demonstrated by the } \\
\text { inhibitory effect of the } \\
\text { l-carnitine analog, one } \\
\text { of the predicted } \\
\text { antimetabolites, on the } \\
\text { proliferation of the } \\
\text { HepG2 CCL. }\end{array}$ \\
\hline
\end{tabular}

GEMs to identify Found that taxane-treated breast cancer cells metabolic inhibitors to

[176] administrate with drug combinations in adaptive therapies undergo a metastable transition in which they

depend more on oxidative and non-oxidative glucose metabolism conferring them resistance to doxorubicin. Predict that these rewired cancer cells can be effectively targeted when a glucose metabolism inhibitor is co-administered with doxorubicin.

$\begin{array}{cc}\text { Prism } & \text { In vivo experiments } \\ \text { (GraphPad) } & \text { with mouse models, } \\ \text { patient explant system. }\end{array}$

Central C and N RMGEM to study the interplay between glucose and glutamine for biomass formation in ammonia

GEMs to explore microenvironment. Perform Warburg effect

[177] cancer metabolism biology quantitative. Used the RMGEM to do FBA to study all possible glutamine fates. Found that glutamine can supply $\mathrm{C}$ sources for cell energy production and can be used as a $\mathrm{C}$ and $\mathrm{N}$ source to synthesize essential metabolites.

FAME

$\mathrm{HPaA}$ to explore the prognosis of each protein in 17 major cancers. Uses CSGEMs to identify tumor growth involved genes. Based on

GEMs to explore [178] cancer metabolism biology transcriptomics of $\sim 8000$ patients with clinical metadata. Revealed that survival is associated with upregulation mitosis and cell growth genes while downregulated genes are mostly involved in cellular differentiation.

$\begin{array}{cc}\text { Kaplan-Meier } & \text { HPaA [178], } \\ \text { plots, PCA } & \text { TCGA, Godels, } \\ & \text { GDC }\end{array}$

Kaplan-Meie GDC
Immunohistochemistry.
Merged 374 CSGEMs from the HPaA to reconstruct a generic CRC GEM. Identified the mayor differences between tumor and normal samples in terms of highly perturbed

CSGEMs to explore cancer metabolism biology metabolites by applying modules reporter metabolite and reporter subnetworks algorithms. Mayor differences were related to the glutathione, arginine and proline metabolic reprogramming.
PIANO (R)

(KEGG and GO

enrichment analysis), CRC

(Bioprofiler analysis),

RAVEN,

Kaplan-Meier survival analysis, $\log$-rank $p$-value

HMR 2.0 and proteomics data in HPA to construct consensus hepatocytes GEM

GEMs to explore

[71] cancer metabolism biology
(iHepatocytes2322) that improves previous

GEMs including an extensive description of

lipid metabolism. GEM used to analyze transcriptomics data from non-alcoholic fatty liver disease patients.

$\begin{array}{lc}\text { INIT, Reporter } & \\ \text { Subnetwork } & \text { HPA, } \\ \text { analysis } & \text { Uniprot, } \\ \text { checkTasks } & \text { GEO } \\ \text { (RAVEN), } & \\ \text { RAVEN } & \end{array}$

HpaA,

BioModels,

TCGA, GO

GDC
ODC1, SMOX, SRM

and SAT validated

in vivo and in vitro, using 15 patients and 4 CRC CCLs.

Hepatocytes biological functions of hepatocyte-specific GEM demonstrated by simulating 256 metabolic functions of HepatoNet, using checkTasks / fitTasks (RAVEN).

Qualitative comparison between predicted metabolic consump-

GPR called S-GPR considering transcripts GEMs to explore [90] cancer metabolism biology stoichiometry. Investigate PC cells metabolic effects chronic exposure to an endocrine disruptor.

\section{Mann-Whitney test, FASIMU, \\ Gimme, Mat, pFBA MADE \\ HMD, Lipid \\ Maps, HMA, GEO}

the metabolomic and

lipidomic experimental measurements. 
Table 3. Cont.

\begin{tabular}{|c|c|c|c|c|c|}
\hline Reference & Category & Concept & Tools Used & Databases & Type of Validation \\
\hline [180] & $\begin{array}{l}\text { Warburg effect } \\
\text { computer } \\
\text { metabolic } \\
\text { modeling }\end{array}$ & $\begin{array}{c}\text { Study common and robust metabolic } \\
\text { pathways supporting cancer cells (glycolysis, } \\
\text { TCA cycle, pentose phosphate, glutaminolysis } \\
\text { and oxidative phosphorylation). Propose } \\
\text { metabolic targets for anticancer treatments by } \\
\text { a constraint-based modeling on integrated } \\
\text { data. }\end{array}$ & COBRA toolbox & GEO & $\begin{array}{l}\text { Verified that the in } \\
\text { silico kinetic growth } \\
\text { curve exhibit a } \\
\text { comparable behavior } \\
\text { with the experimentally } \\
\text { obtained from Hela } \\
\text { CCLs. }\end{array}$ \\
\hline$[84]$ & $\begin{array}{l}\text { Warburg effect } \\
\text { computer } \\
\text { metabolic } \\
\text { modeling }\end{array}$ & $\begin{array}{l}\text { GEM human metabolic network accounting } \\
\text { stoichiometry and enzyme solvent capacity. } \\
\text { Demonstrate that Warburg effect happens } \\
\text { since the metabolic adaptation of cancer cells } \\
\text { to increase biomass production rate. }\end{array}$ & & $\begin{array}{l}\text { BRENDA, } \\
\text { SABIO-RK }\end{array}$ & $\begin{array}{l}\text { Correlation between } \\
\text { enzyme concentration } \\
\text { predictions and } \\
\text { expression of } 1269 \\
\text { metabolic genes from } \\
60 \text { NCI CCLs. } \\
\text { Validated against } 1000 \\
\text { flux distributions of } \\
\text { two models by ACHR } \\
\text { sampling. }\end{array}$ \\
\hline [181] & $\begin{array}{l}\text { Warburg effect } \\
\text { computer } \\
\text { metabolic } \\
\text { modeling }\end{array}$ & $\begin{array}{l}\text { Expand metabolic efficiency notion by ATP } \\
\text { production FBM constrained by glucose } \\
\text { uptake and solvent capacities in the cell's } \\
\text { cytoplasm. Found that at low glucose uptake } \\
\text { rates mitochondrial respiration is the most } \\
\text { efficient pathway for ATP generation while } \\
\text { when increasing glucose uptake rates a } \\
\text { gradual switch to aerobic glycolysis achieves } \\
\text { ATP highest rate since it is more efficient for } \\
\text { the required solvent capacity. }\end{array}$ & & & $\begin{array}{l}\text { Agreement between the } \\
\text { experimentally } \\
\text { determined fluxes and } \\
\text { the model predictions. }\end{array}$ \\
\hline$[182]$ & $\begin{array}{l}\text { Warburg effect } \\
\text { computer } \\
\text { metabolic } \\
\text { modeling }\end{array}$ & $\begin{array}{l}\text { Constraint-based modeling with E-Flux } \\
\text { integrating } 13 \text { different cancer cell } \\
\text { transcriptomics with Recon } 1 \text { generic model. } \\
\text { Found that metabolic changes distributions } \\
\text { are similar in different cancer types, } \\
\text { supporting that Warburg effect is a general } \\
\text { metabolic adaptation. }\end{array}$ & $\begin{array}{c}\text { E-Flux, } \\
\text { GeWorkbench } \\
\text { 2.4.0, COBRA }\end{array}$ & GEO & \\
\hline
\end{tabular}

Abbreviations: (C) carbon, (CCL) cancer cell line, (CRC) colorectal cancer, (CSGEM) cancer-specific GEM, (DIRAC) DIfferential RAnk Conservation, (GDC) Genomic Data Commons, (GEO) Gene Expression Omnibus, (GO) Gene Ontology, (HCC) Hepatocellular Carcinoma, (HMA) Human Metabolic Atlas, (HMD) Human Metabolome Database, (HPA) Human Protein Atlas, (HpaA) Human Protein Pathology Atlas, (N) nitrogen, (PC) prostate cancer, (RMGEM) reduced metabolic GEM.

\subsubsection{Modeling the Metabolic Crosstalk between Cell Populations}

To model the metabolic crosstalk between multiple cell populations, such as substrate competition or cross-feeding (i.e., the metabolic products of a cell population are used as substrates for a second cell population), multiple GEMs, each representing a subpopulation, can be coupled (i.e., connected to a shared extracellular compartment). This approach has been pioneered in the modeling of bacterial communities, where metagenomic sequencing data are used to build models of specific bacteria species present in the community, which are subsequently coupled [183]. This has enabled modeling the metabolic host-microbiome interactions in the human gut and their role in health and disease [184,185]. Additionally, 32 organ and cell-type-specific GEMs have been integrated to build physiologically constrained female and male whole-body metabolic models that in addition of predicting how the microbiome may modulate human metabolism, they can also predict organ metabolic essentiality, biomarkers of inherited metabolic diseases and inter-organ metabolic cycles [186]. However, modeling the crosstalk between cancer and immune population in the cancer stroma is a major challenge due to the intermingling of the different cell populations, to the tumor heterogeneity and to the dynamics changes happening both in cancer and in the immune populations. Building a context-specific GEM by using bulk transcriptomics, proteomics or metabolomics will result in a single model representing the average profile of the tumor, and, thus, it will be unable to capture metabolic heterogeneity, nor the metabolic crosstalk between cell populations. However, thanks to the use of 
single-cell RNA-Seq (scRNA-Seq) is possible to analyze the composition and the population changes. For example, thanks to the use of scRNA-Seq, Wu et al. [187] discovered rare cell types in non-small-cell lung cancer (NSCLC) such as follicular dendritic cells and T-helper 17 cells. Lin et al. [188], using scRNA-Seq, discovered in pancreatic ductal adenocarcinoma (PDAC) distinct cell types in primary and metastatic PDAC tissues including tumor cells, endothelial cells, cancer-associated fibroblasts (CAFs) and immune cells. Cancer cells have higher inter-patient heterogeneity, whereas stromal cells are more homogenous across patients. Furthermore, they found that the expression levels of cell-type-specific markers for EMT+ cancer cells, activated CAFs and endothelial cells significantly associated with patient survival. Moreover, in PDAC, Dominguez et al. [189] identified a population of CAFs that are programmed by TGF $\beta$ and express the leucine-rich repeat containing 15 (LRRC15) protein. These LRRC15+ CAFs surround tumor islets and are absent from normal pancreatic tissue. The integration of the information provided by scRNA-Seq with GEMs has led to the development of approaches such as popFBA or single-cell FBA.

\section{PopFBA}

PopFBA [190] is an extension to FBA to study the cooperating metabolism through the exchange of a defined set of metabolites within the presence of several subpopulations in a population sharing a common environment. Spatial proximity dictates differences of the distinct components in the tumor for nutrient exchange with the plasma and other cells within the populations. A single GEM is used as a building block, and the population model consists of multiple clones with identical stoichiometry, constraints and sharing the plasma nutrient supply. Linear programming optimization is used to find the optimal growth rate of the entire tumor mass, allowing us to investigate the cooperation among different clones and the different metabolic strategies taken. However, because all the models share the same stoichiometry, this approach is unlikely to encapsulate the metabolic differences between distinct cancer and immune cell populations. Therefore, popFBA only allows us to explore how metabolic heterogeneity and cooperation phenomena affect the overall growth of cancer cell populations.

\section{Single-Cell FBA (scFBA)}

It is possible to add constraints on the single-cell fluxes by using single-cell transcriptomes derived from scRNA-Seq experiments. Coupling the information of scRNA-Seq with extracellular fluxes within the FBA steady-state modeling framework allows us to obtain feasible solutions for the prediction of intracellular fluxes. ScFBA [191] takes as input a template metabolic network map and an scRNA-Seq matrix. It also allows us to employ the information on bulk expression profiles. Single-cell fluxomes and possible metabolic interactions among them are predicted by using scFBA, starting from bulk extracellular fluxes and a multiscale model with scRNA-Seq that optimize an individual biomass function to identify the possible combination of single-cell steady states given the constraints on scRNA-Seq and extracellular bulk fluxes. The flux distribution of each reaction and each cell interacts with other cells in the population via release/uptake of metabolites into/from the TME. ScFBA first creates a multiscale population model: for each single cell in the bulk, the same stoichiometry of the metabolic network map is first used, and then the constraints on the fluxes of the individual networks are integrated by assigning flux boundaries as a function of the expression state proportionally to the activity score of that reaction in each cell. This procedure is implemented without creating context-specific models from generic ones. Finally, each single cell in the bulk is represented by a single-cell compartment of the multiscale model. Thus, each single-cell compartment has different metabolic parameters and allows cooperation between cells, as well as the flow of metabolites between the TME and the cells. 


\section{Discussion}

The immune system is critical in fighting cancer, as the immune response can lead to the destruction of cancer cells. Immune cells and cancer cells compete for nutrients within the TME. Some cancer cells gain mutations and change their characteristics to evade the immunosurveillance by several mechanisms. Cancer cells can reprogram their metabolism to enhance proliferation, migration and invasion of distant tissues. Many of these metabolic changes result in an increased uptake of nutrients from the TME, limiting the availability of nutrients for the cells from the immune infiltrate. Knowledge about the utilization of reprogrammed metabolic mechanisms requires the quantification of metabolic fluxes, and GEMs allow us to make computational predictions of the metabolic fluxes of cancer cells. Modeling metabolism at the genome-scale requires us to reverse-engineer the network structure, and then to add stoichiometric, thermodynamic and/or enzymatic capacity constraints on the network. Using transcriptomic and proteomic data, we deem that it is possible to identify the presence of the enzymes that catalyze the active reactions in a given cell and tissue type. Metabolomic data can be used to determine the rate at which metabolites are produced or consumed from the extracellular medium (i.e., extracellular fluxes) and can have a significant effect on predictions [191]. Extracellular fluxes can be measured ex vivo with experiments that have a controlled extracellular medium. Indeed, culturing cells from human biopsies from which transcriptomic or proteomic data are obtained and measuring metabolite concentrations in spent medium constitute a first attempt towards cancer personalized medicine [192]. To test therapies that remain in the preclinical stage, while minimizing the possible toxicity risks, if patient consent is available, it is possible to use a tumor sample for in vitro manipulation with primary cell culture or organoids or even subcutaneously transferring into mice or zebrafish for growth to obtain patient-derived xenografts in which we can test different drugs and concentrations [193].

In this work, we reviewed the state-of-the-art in modeling the tumor metabolism at the genome-scale and the crosstalk between cancer and immune cell metabolism in the context of the existing framework for constraint-based modeling and/or genome-scale metabolic reconstruction, including a number of approaches involving the application of GEMs. We also addressed the population's heterogeneity problem, which is that the actual cellular population composition is undetermined, and thus, the average values do not describe the population fluxes well; therefore, an additional layer of complexity must be modeled by using specific methods. We posit that such a framework has yet untapped potential to model the metabolic crosstalk of cancer cells and immune cell populations that plays a key role in cancer progression and could potentially pave the way for a new generation of therapies that potentiate antitumoral immune response.

The heterogeneity of the tumor metabolic reprogramming is not fully understood, as there are experimental limitations for the metabolomics studies, in that, although they are able to provide insights into the cellular metabolic status of cells, there is still a lack of information regarding the cause or effect of metabolite changes and in silico models. Integrating multi-omics data may provide a broader picture, thus enabling the identification of the regulatory mechanisms underlying in the pathophysiology of complex diseases, such as cancer [194]. The TME constitutes a complex adaptive ecological system, and due to the difficulty in modeling the interactions between multiple cell types modeling, the TME remains challenging. Capuani et al. [195] reconstructed a large-scale in silico metabolic model of interacting human CAFs and tumor cells for the lactate shuttle. Shan et al. [196] implemented a multiscale modeling approach to interrogate the implication of the TME on the Warburg effect, the reverse Warburg effect and glutamine addiction. With the use of the ScFBA algorithm developed by Damiani et al. [191], it was possible to model a heterogeneous cancer cell population and represent the metabolite exchange between different cell types. Because TAMs can be induced by oncometabolites that activate in macrophages cancer-promoting pathways, reversing the polarization of protumoral TAMs is likely to be an effective strategy against cancer [197]. In this direction, a new avenue constitutes to interconvert pro-inflammatory M1 (with the ability to metabolize arginine to nitric oxide) to 
wound-healing M2 (with the ability to metabolize arginine to ornithine) [198] populations of macrophages by using approaches such as depletion of TAMs, reprogramming of TAMs toward M1 polarized macrophages, acting over the recruitment of monocytes into the tumor or inhibiting the endothelial-mesenchymal transition [199]. In this line, Li et al. [199] used an interaction network of cancer cells and macrophages to investigate how the polarization of macrophages can interact with the epithelial-mesenchymal plasticity of cancer cells. This study suggested that therapies against malignancy that enhance M1 domination and cancer-free steady-state require mechanisms that synergistically promote the transition of mesenchymal to epithelial cells and keep a low growth rate of mesenchymal cells.

The TME and the ECM affect tumor cell metabolism, control cell polarity, migration, proliferation and oncogenic transformation; consequently, it is essential to understand the contribution of nutrient transit from the TME to support cancer cells' growth under nutrient-starvation conditions [70]. CAFs represent a significant proportion of the TME, and they have been shown to contribute to tumor growth, metastasis and resistance to therapy through the regulation of cancer metabolism, as they secrete metabolites and generate a more fibrotic ECM [70]. Integrins are plasma membrane receptors that mediate cell-ECM interactions. Modeling the crosstalk between CAFs and cancer cells, integrin trafficking, nutrient signaling and different mechanisms through which cancer cells can exploit different nutrient sources from the TME will enormously contribute to understanding the metabolic plasticity and responsiveness and resistance to therapy of the cancer cells.

Future developments will likely involve methodological and translational advancements, such as using richer datasets with additional data sources from different cell types from scRNA-Seq and clinical samples that include the information of cellular regulatory mechanisms or modeling interactions of cancer cells with the surrounding cells from the TME, as well as predicting and circumventing the drug resistance of metabolic cancer drugs by building integrated kinetic and stoichiometric models of cancer metabolism. For example, The Cancer Genome Atlas (TCGA) database (https:/ / www.cancer.gov/tcga [Accessed on 1 January 2020]) is a good resource of cancer high-throughput-omics data that can be collected and integrated to holistically perform analysis, using GEMs. Outside of cancer, these bottom-up systems' biology approaches that drive drug repurposing and drug discovery can be used to identify therapies for other diseases [200].

\section{Conclusions}

Expanding the understanding of the dynamic interplay of numerous cell types, such as cancer cells, immune cells and stromal cells within TME is likely key to develop effective cancer therapies. Cancer cells reprogram their metabolism to capture substrates needed to sustain proliferation with increased avidity and produce toxic metabolic byproducts, inhibiting immune cells' function and promoting immune evasion. Thus therapies selectively targeting the metabolic crosstalk between cancer and immune cells could potentially restore immune function within the tumor, leading to improved therapeutic outcomes. In this regard, the GEMs approaches reviewed in this work are promising tools to analyze the metabolic crosstalk underlying immunosuppression in the TME, stratifying patients, identifying key players promoting immunosuppression in each patient strata, and repositioning drugs to target them.

Author Contributions: Conceptualization, I.F., C.F., M.C. and M.J.A.-B.; resources, M.J.A.-B.; writingoriginal draft preparation, I.F., C.F., M.C. and M.J.A.-B.; writing-review and editing, I.F., C.F., M.C. and M.J.A.-B.; visualization, I.F.; supervision, M.C. and M.J.A.-B.; project administration, M.C. and M.J.A.-B.; funding acquisition, M.J.A.-B. All authors have read and agreed to the published version of the manuscript. 
Funding: This research has been funded for M.J.A.-B. by Diputación Foral de Guipúzcoa, Spain (DFG109/20), Ministry of Science and Innovation of Spain MICINN/AEI/FEDER, UE, (PID2020119715GB-I00) and European Union FET project Circular Vision (H2020-FETOPEN, Project 899417). M.C. by Agència de Gestió d'Ajuts Universitaris i de Recerca (2017SGR1033) from the Catalan Government, ICREA Academia, MICINN/AEI/FEDER, UE (PID2020-115051RB-I00), and Instituto de Salud Carlos III (CIBEREHD, CB17/04/00023). C.F. received support from the Spanish National Bioinformatics Institute (INB-ISCIII-ES-ELIXIR).

Conflicts of Interest: The authors declare no conflict of interest.

\section{References}

1. Lyssiotis, C.A.; Kimmelman, A.C. Metabolic Interactions in the Tumor Microenvironment. Trends Cell Biol. 2017, $27,863-875$. [CrossRef]

2. Seager, R.J.; Hajal, C.; Spill, F.; Kamm, R.D.; Zaman, M.H. Dynamic interplay between tumour, stroma and immune system can drive or prevent tumour progression. Converg. Sci. Phys. Oncol. 2017, 3, 034002. [CrossRef] [PubMed]

3. Muenst, S.; Läubli, H.; Soysal, S.; Zippelius, A.; Tzankov, A.; Hoeller, S. The immune system and cancer evasion strategies: Therapeutic concepts. J. Intern. Med. 2016, 279, 541-562. [CrossRef] [PubMed]

4. Wang, J.; Li, D.; Cang, H.; Guo, B. Crosstalk between cancer and immune cells: Role of tumor-associated macrophages in the tumor microenvironment. Cancer Med. 2019, 8, 4709-4721. [CrossRef]

5. Liu, Y.; Zeng, G. Cancer and innate immune system interactions: Translational potentials for cancer immunotherapy. J. Immunother. 2012, 35, 299-308. [CrossRef] [PubMed]

6. Cassim, S.; Pouyssegur, J. Tumor Microenvironment: A Metabolic Player that Shapes the Immune Response. Int. J. Mol. Sci. 2019, 21, 157. [CrossRef]

7. Kishton, R.J.; Sukumar, M.; Restifo, N.P. Metabolic Regulation of T Cell Longevity and Function in Tumor Immunotherapy. Cell Metab. 2017, 26, 94-109. [CrossRef]

8. Unanue, E.R.; Turk, V.; Neefjes, J. Variations in MHC Class II Antigen Processing and Presentation in Health and Disease. Annu. Rev. Immunol. 2016, 34, 265-297. [CrossRef] [PubMed]

9. Hivroz, C.; Chemin, K.; Tourret, M.; Bohineust, A. Crosstalk between T Lymphocytes and Dendritic Cells. Crit. Rev. Immunol. 2012, 32, 139-155. [CrossRef]

10. Valenzuela, J.; Schmidt, C.; Mescher, M. The Roles of IL-12 in Providing a Third Signal for Clonal Expansion of Naive CD8 T Cells. J. Immunol. 2002, 169, 6842-6849. [CrossRef]

11. Tian, Y.; Babor, M.; Lane, J.; Schulten, V.; Patil, V.S.; Seumois, G.; Rosales, S.L.; Fu, Z.; Picarda, G.; Burel, J.; et al. Unique phenotypes and clonal expansions of human CD4 effector memory T cells re-expressing CD45RA. Nat. Commun. 2017, 8, 1-13. [CrossRef]

12. Akbar, A.N.; Terry, L.; Timms, A.; Beverley, P.; Janossy, G. Loss of CD45R and gain of UCHL1 reactivity is a feature of primed T cells. J. Immunol. 1988, 140, 2171-2178.

13. Koch, S.; Larbi, A.; Derhovanessian, E.; Özcelik, D.; Naumova, E.; Pawelec, G. Multiparameter flow cytometric analysis of CD4 and CD8 T cell subsets in young and old people. Immun. Ageing 2008, 5, 6. [CrossRef] [PubMed]

14. Lim, A.R.; Rathmell, W.K.; Rathmell, J.C. The tumor microenvironment as a metabolic barrier to effector T cells and immunotherapy. Elife 2020, 9, e55185. [CrossRef] [PubMed]

15. Yin, Z.; Bai, L.; Li, W.; Zeng, T.; Tian, H.; Cui, J. Targeting T cell metabolism in the tumor microenvironment: An anti-cancer thera-peutic strategy. J. Exp. Clin. Cancer Res. 2019, 38, 403. [CrossRef]

16. Han, Y.; Liu, D.; Li, L. PD-1/PD-L1 pathway: Current researches in cancer. Am. J. Cancer Res. 2020, 10, 727-742.

17. Ohaegbulam, K.C.; Assal, A.; Lazar-Molnar, E.; Yao, Y.; Zang, X. Human cancer immunotherapy with antibodies to the PD-1 and PD-L1 pathway. Trends Mol. Med. 2015, 21, 24-33. [CrossRef] [PubMed]

18. Pardoll, D.M. The blockade of immune checkpoints in cancer immunotherapy. Nat. Rev. Cancer 2012, 12, 252-264. [CrossRef] [PubMed]

19. Le Bourgeois, T.; Strauss, L.; Aksoylar, H.I.; Daneshmandi, S.; Seth, P.; Patsoukis, N.; Boussiotis, V.A. Targeting T Cell Metabolism for improvement of cancer immunotherapy. Front. Oncol. 2018, 8, 237. [CrossRef]

20. Patsoukis, N.; Bardhan, K.; Chatterjee, P.; Sari, D.; Liu, B.; Bell, L.N.; Karoly, E.D.; Freeman, G.J.; Petkova, V.; Seth, P.; et al. PD-1 alters T-cell metabolic reprogramming by inhibiting glycolysis and promoting lipolysis and fatty acid oxidation. Nat. Commun. 2015, 6, 6692. [CrossRef]

21. Andrejeva, G.; Rathmell, J.C. Similarities and Distinctions of Cancer and Immune Metabolism in Inflammation and Tumors. Cell Metab. 2017, 26, 49-70. [CrossRef]

22. Wang, Y.; Ma, S.; Ruzzo, W.L. Spatial modeling of prostate cancer metabolism reveals extensive heterogeneity and selective vulnerabilities. BioRxiv 2019, 719294. [CrossRef]

23. Motamedian, E.; Ghavami, G.; Sardari, S. Investigation on metabolism of cisplatin resistant ovarian cancer using a genome scale metabolic model and microarray data. Iran. J. Basic Med. Sci. 2015, 18, 267-276. [PubMed] 
24. Kim, H.U.; Kim, T.Y.; Lee, S.Y. Genome-scale metabolic network analysis and drug targeting of multi-drug resistant pathogen Acinetobacter baumannii AYE. Mol. BioSyst. 2009, 6, 339-348. [CrossRef] [PubMed]

25. Renner, K.; Singer, K.; Koehl, G.E.; Geissler, E.K.; Peter, K.; Siska, P.J.; Kreutz, M. Metabolic Hallmarks of Tumor and Immune Cells in the Tumor Microenvironment. Front. Immunol. 2017, 8, 248. [CrossRef]

26. Xia, L.; Oyang, L.; Lin, J.; Tan, S.; Han, Y.; Wu, N.; Yi, P.; Tang, L.; Pan, Q.; Rao, S.; et al. The cancer metabolic reprogramming and immune response. Mol. Cancer 2021, 20,1-21. [CrossRef] [PubMed]

27. Domblides, C.; Lartigue, L.; Faustin, B. Control of the Antitumor Immune Response by Cancer Metabolism. Cells 2019, 8, 104. [CrossRef] [PubMed]

28. Singer, K.; Cheng, W.-C.; Kreutz, M.; Ho, P.-C.; Siska, P.J. Immunometabolism in cancer at a glance. Dis. Model. Mech. 2018, 11, 034272. [CrossRef]

29. Schulze, A.; Yuneva, M. The big picture: Exploring the metabolic cross-talk in cancer. Dis. Model. Mech. 2018, 11, dmm036673. [CrossRef]

30. Rabinovich, G.A.; Gabrilovich, D.; Sotomayor, E.M. Immunosuppressive Strategies that are Mediated by Tumor Cells. Annu. Rev. Immunol. 2007, 25, 267-296. [CrossRef]

31. Warburg, O. On the Origin of Cancer Cells. Science 1956, 123, 309-314. [CrossRef] [PubMed]

32. Marbaniang, C.; Kma, L. Dysregulation of Glucose Metabolism by Oncogenes and Tumor Suppressors in Cancer Cells. Asian Pac. J. Cancer Prev. 2018, 19, 2377-2390. [CrossRef]

33. Tarrado-Castellarnau, M.; de Atauri, P.; Cascante, M. Oncogenic regulation of tumor metabolic reprogramming. Oncotarget 2016, 7, 62726-62753. [CrossRef]

34. Gillies, R.J.; Gatenby, R.A. Metabolism and Its Sequelae in Cancer Evolution and Therapy. Cancer J. 2015, 21, 88-96. [CrossRef] [PubMed]

35. Nagao, A.; Kobayashi, M.; Koyasu, S.; Chow, C.C.T.; Harada, H. HIF-1-Dependent Reprogramming of Glucose Metabolic Pathway of Cancer Cells and Its Therapeutic Significance. Int. J. Mol. Sci. 2019, 20, 238. [CrossRef] [PubMed]

36. Harris, A.L. Hypoxia-A key regulatory factor in tumour growth. Nat. Rev. Cancer 2002, 2, 38-47. [CrossRef] [PubMed]

37. Pastorekova, S.; Gillies, R.J. The role of carbonic anhydrase IX in cancer development: Links to hypoxia, acidosis, and beyond. Cancer Metastasis Rev. 2019, 38, 65-77. [CrossRef]

38. Ames, S.; Pastorekova, S.; Becker, H.M. The proteoglycan-like domain of carbonic anhydrase IX mediates non-catalytic facilitation of lactate transport in cancer cells. Oncotarget 2018, 9, 27940-27957. [CrossRef]

39. Siska, P.J.; Kim, B.; Ji, X.; Hoeksema, M.D.; Massion, P.P.; Beckermann, K.E.; Wu, J.; Chi, J.-T.; Hong, J.; Rathmell, J.C. Fluorescencebased measurement of cystine uptake through $\mathrm{xCT}$ shows requirement for ROS detoxification in activated lymphocytes. $J$. Immunol. Methods 2016, 438, 51-58. [CrossRef]

40. Jun, J.C.; Rathore, A.; Younas, H.; Gilkes, D.; Polotsky, V.Y. Hypoxia-Inducible Factors and Cancer. Curr. Sleep Med. Rep. 2017, 3, 1-10. [CrossRef]

41. Masoud, G.N.; Li, W. HIF-1 $\alpha$ pathway: Role, regulation and intervention for cancer therapy. Acta Pharm. Sin. B 2015, 5, 378-389. [CrossRef]

42. Laukka, T.; Mariani, C.J.; Ihantola, T.; Cao, J.Z.; Hokkanen, J.; Kaelin, W.G., Jr.; Godley, L.A.; Koivunen, P. Fumarate and Succinate Regulate Expression of Hypoxia-inducible Genes via TET Enzymes. J. Biol. Chem. 2016, 291, 4256-4265. [CrossRef]

43. Murdoch, C.; Giannoudis, A.; Lewis, C.E. Mechanisms regulating the recruitment of macrophages into hypoxic areas of tumors and other ischemic tissues. Blood 2004, 104, 2224-2234. [CrossRef]

44. Lewis, C.; Murdoch, C. Macrophage Responses to Hypoxia: Implications for Tumor Progression and Anti-Cancer Therapies. Am. J. Pathol. 2005, 167, 627-635. [CrossRef]

45. Mandl, M.; Depping, R. ARNT is a potential direct HIF-1 target gene in human Hep3B hepatocellular carcinoma cells. Cancer Cell Int. 2017, 17, 77. [CrossRef]

46. Yang, H.; Geng, Y.; Wang, P.; Zhou, Y.; Yang, H.; Huo, Y.; Zhang, H.; Li, Y.; He, H.; Tian, X.; et al. Extracellular ATP promotes breast cancer invasion and epithelial-mesenchymal transition via hypoxia-inducible factor $2 \alpha$ signaling. Cancer Sci. 2019, 110, 2456-2470. [CrossRef]

47. Jia, Y.; Hao, S.; Jin, G.; Li, H.; Ma, X.; Zheng, Y.; Xiao, D.; Wang, Y. Overexpression of ARNT2 is associated with decreased cell pro-liferation and better prognosis in gastric cancer. Mol. Cell Biochem. 2019, 450, 97-103. [CrossRef] [PubMed]

48. Yazdani, B.; Sirous, H. HIF3A: A Potent Prognostic Biomarker in Different Kinds of Cancer. Preprints 2021, 2021040265. [CrossRef]

49. Saravia, J.; Raynor, J.L.; Chapman, N.M.; Lim, S.A.; Chi, H. Signaling networks in immunometabolism. Cell Res. 2020, 30, 328-342. [CrossRef] [PubMed]

50. Wang, Y.-P.; Lei, Q.-Y. Metabolite sensing and signaling in cell metabolism. Signal Transduct. Target. Ther. 2018, 3, 1-9. [CrossRef] [PubMed]

51. Robles-Flores, M.; Moreno-Londoño, A.P.; Castañeda-Patlán, M.C. Signaling Pathways Involved in Nutrient Sensing Control in Cancer Stem Cells: An Overview. Front. Endocrinol. 2021, 12, 627745. [CrossRef] [PubMed]

52. Eniafe, J.; Jiang, S. The functional roles of TCA cycle metabolites in cancer. Oncogene 2021, 40, 3351-3363. [CrossRef] [PubMed]

53. Kedia-Mehta, N.; Finlay, D.K. Competition for nutrients and its role in controlling immune responses. Nat. Commun. 2019, 10, 1-8. [CrossRef] 
54. Wei, J.; Raynor, J.; Nguyen, T.-L.M.; Chi, H. Nutrient and Metabolic Sensing in T Cell Responses. Front. Immunol. 2017, 8, 247. [CrossRef]

55. Blagih, J.; Coulombe, F.; Vincent, E.; Dupuy, F.; Vazquez, G.G.; Yurchenko, E.; Raissi, T.C.; van der Windt, G.J.; Viollet, B.; Pearce, E.L.; et al. The Energy Sensor AMPK Regulates T Cell Metabolic Adaptation and Effector Responses In Vivo. Immunity 2015, 42, 41-54. [CrossRef]

56. Dembitz, V.; Lalic, H. The Role of AMPK/mTOR Modulators in the Therapy of Acute Myeloid Leukemia. Curr. Med. Chem. 2019, 26, 2208-2229. [CrossRef]

57. Zhao, W.; Peng, F.; Shu, M.; Liu, H.; Hou, X.; Wang, X.; Ye, J.; Zhao, B.; Wang, K.; Zhong, C.; et al. Isogambogenic Acid Inhibits the Growth of Glioma Through Activation of the AMPK-mTOR Pathway. Cell. Physiol. Biochem. 2017, 44, 1381-1395. [CrossRef] [PubMed]

58. Liu, X.; Chhipa, R.R.; Nakano, I.; Dasgupta, B. The AMPK Inhibitor Compound C Is a Potent AMPK-Independent Antiglioma Agent. Mol. Cancer Ther. 2014, 13, 596-605. [CrossRef]

59. Yue, W.; Yang, C.S.; DiPaola, R.S.; Tan, X.L. Repurposing of metformin and aspirin by targeting AMPK-mTOR and inflammation for pancreatic cancer prevention and treatment. Cancer Prev. Res. (Phila) 2014, 7, 388-397. [CrossRef]

60. Roudsari, N.M.; Lashgari, N.A.; Momtaz, S.; Abaft, S.; Jamali, F.; Safaiepour, P.; Narimisa, K.; Jackson, G.; Bishayee, A.; Rezaei, N.; et al. Inhibitors of the PI3K/Akt/mTOR Pathway in Prostate Cancer Chemoprevention and Inter-vention. Pharmaceutics 2021, 13, 1195. [CrossRef]

61. Zou, Y.-F.; Xie, C.-W.; Yang, S.-X.; Xiong, J.-P. AMPK activators suppress breast cancer cell growth by inhibiting DVL3-facilitated Wnt/ $\beta$-catenin signaling pathway activity. Mol. Med. Rep. 2016, 15, 899-907. [CrossRef]

62. Xie, W.-Y.; Zhou, X.-D.; Yang, J.; Chen, L.-X.; Ran, D.-H. Inhibition of autophagy enhances heat-induced apoptosis in human non-small cell lung cancer cells through ER stress pathways. Arch. Biochem. Biophys. 2016, 607, 55-66. [CrossRef] [PubMed]

63. Rogers, R.S.; Bhattacharya, J. When Cells Become Organelle Donors. Physiology 2013, 28, 414-422. [CrossRef] [PubMed]

64. Moschoi, R.; Imbert, V.; Nebout, M.; Chiche, J.; Mary, D.; Prebet, T.; Saland, E.; Castellano, R.; Pouyet, L.; Collette, Y.; et al. Protective mitochondrial transfer from bone marrow stromal cells to acute myeloid leukemic cells during chemotherapy. Blood 2016, 128, 253-264. [CrossRef] [PubMed]

65. Yan, Y.; Chen, X.; Wang, X.; Zhao, Z.; Hu, W.; Zeng, S.; Wei, J.; Yang, X.; Qian, L.; Zhou, S.; et al. The effects and the mechanisms of autophagy on the cancer-associated fibroblasts in cancer. J. Exp. Clin. Cancer Res. 2019, 38, 1-12. [CrossRef]

66. de la Cruz-López, K.G.; Castro-Muñoz, L.J.; Reyes-Hernández, D.O.; García-Carrancá, A.; Manzo-Merino, J. Lactate in the Regulation of Tumor Microenvironment and Therapeutic Approaches. Front. Oncol. 2019, 9, 1143. [CrossRef]

67. Zhao, H.; Yang, L.; Baddour, J.; Achreja, A.; Bernard, V.; Moss, T.; Marini, J.C.; Tudawe, T.; Seviour, E.; Lucas, F.A.S.; et al. Tumor microenvironment derived exosomes pleiotropically modulate cancer cell metabolism. eLife 2016, 5, e10250. [CrossRef]

68. Nallanthighal, S.; Heiserman, J.P.; Cheon, D.-J. The Role of the Extracellular Matrix in Cancer Stemness. Front. Cell Dev. Biol. 2019, 7, 86. [CrossRef]

69. Sazeides, C.; Le, A. Metabolic relationship between cancer-associated fibroblasts and cancer cells. In the heterogeneity of cancer metabolism. Adv. Exp. Med. Biol. 2018, 1063, 149-165.

70. Nazemi, M.; Rainero, E. Cross-Talk between the Tumor Microenvironment, Extracellular Matrix, and Cell Metabolism in Cancer. Front. Oncol. 2020, 10, 239. [CrossRef]

71. Mardinoglu, A.; Agren, R.; Kampf, C.; Asplund, A.; Nookaew, I.; Jacobson, P.; Walley, A.J.; Froguel, P.; Carlsson, L.M.; Uhlen, M.; et al. Integration of clinical data with a genome-scale metabolic model of the human adipocyte. Mol. Syst. Biol. 2013, 9, 649. [CrossRef]

72. Mardinoglu, A.; Agren, R.; Kampf, C.; Asplund, A.; Uhlen, M.; Nielsen, J. Genome-scale metabolic modelling of hepatocytes reveals serine deficiency in patients with non-alcoholic fatty liver disease. Nat. Commun. 2014, 5, 3083. [CrossRef] [PubMed]

73. Duarte, N.C.; Becker, S.A.; Jamshidi, N.; Thiele, I.; Mo, M.L.; Vo, T.D.; Srivas, R.; Palsson, B.Ø. Global reconstruction of the human metabolic network based on genomic and bibliomic data. Proc. Natl. Acad. Sci. USA 2007, 104, 1777-1782. [CrossRef] [PubMed]

74. Thiele, I.; Swainston, N.; Fleming, R.M.; Hoppe, A.; Sahoo, S.; Aurich, M.K.; Haraldsdottir, H.; Mo, M.L.; Rolfsson, Ó.; Stobbe, M.D.; et al. A community-driven global reconstruction of human metabolism. Nat. Biotechnol. 2013, 31, 419-425. [CrossRef] [PubMed]

75. Brunk, E.; Sahoo, S.; Zielinski, D.C.; Altunkaya, A.; Dräger, A.; Mih, N.; Gatto, F.; Nilsson, A.; Gonzalez, G.A.P.; Aurich, M.K.; et al. Recon3D enables a three-dimensional view of gene variation in human metabolism. Nat. Biotechnol. 2018, 36, 272-281. [CrossRef]

76. Ma, H.; Sorokin, A.; Mazein, A.; Selkov, A.; Selkov, E.; Demin, O.; Goryanin, I. The Edinburgh human metabolic network reconstruc-tion and its functional analysis. Mol. Syst. Biol. 2007, 3, 135. [CrossRef]

77. Nilsson, A.; Nielsen, J. Genome scale metabolic modeling of cancer. Metab. Eng. 2017, 43, 103-112. [CrossRef]

78. O'Brien, E.J.; Monk, J.M.; Palsson, B.O. Using Genome-scale Models to Predict Biological Capabilities. Cell 2015, 161, 971-987. [CrossRef]

79. Yizhak, K.; Chaneton, B.; Gottlieb, E.; Ruppin, E. Modeling cancer metabolism on a genome scale. Mol. Syst. Biol. 2015, 11, 817. [CrossRef]

80. Wang, F.-S.; Wu, W.-H.; Hsiu, W.-S.; Liu, Y.-J.; Chuang, K.-W. Genome-Scale Metabolic Modeling with Protein Expressions of Normal and Cancerous Colorectal Tissues for Oncogene Inference. Metabolites 2019, 10, 16. [CrossRef] 
81. Gatto, F.; Nookaew, I.; Nielsen, J. Chromosome 3p loss of heterozygosity is associated with a unique metabolic network in clear cell renal carcinoma. Proc. Natl. Acad. Sci. USA 2014, 111, E866-E875. [CrossRef]

82. Agren, R.; Bordel, S.; Mardinoglu, A.; Pornputtapong, N.; Nookaew, I.; Nielsen, J. Reconstruction of Genome-Scale Active Metabolic Networks for 69 Human Cell Types and 16 Cancer Types Using INIT. PLoS Comput. Biol. 2012, 8, e1002518. [CrossRef]

83. Folger, O.; Jerby, L.; Frezza, C.; Gottlieb, E.; Ruppin, E.; Shlomi, T. Predicting selective drug targets in cancer through metabolic networks. Mol. Syst. Biol. 2011, 7, 501. [CrossRef]

84. Shlomi, T.; Benyamini, T.; Gottlieb, E.; Sharan, R.; Ruppin, E. Genome-Scale Metabolic Modeling Elucidates the Role of Proliferative Adaptation in Causing the Warburg Effect. PLoS Comput. Biol. 2011, 7, e1002018. [CrossRef] [PubMed]

85. Fan, J.; Ye, J.; Kamphorst, J.J.; Shlomi, T.; Thompson, C.B.; Rabinowitz, J.D. Quantitative flux analysis reveals folate-dependent NADPH production. Nature 2014, 510, 298-302. [CrossRef] [PubMed]

86. Wang, H.; Marcišauskas, S.; Sánchez, B.J.; Domenzain, I.; Hermansson, D.; Agren, R.; Nielsen, J.; Kerkhoven, E.J. RAVEN 2.0: A versatile toolbox for metabolic network reconstruction and a case study on Streptomyces coelicolor. PLoS Comput. Biol. 2018, 14, e1006541. [CrossRef]

87. Yizhak, K.; Le Dévédec, S.E.; Rogkoti, V.M.; Baenke, F.; Boer, V.C.; Frezza, C.; Schulze, A.; Water, B.; Ruppin, E. A computational study of the Warburg effect identifies metabolic targets inhibiting cancer migration. Mol. Syst. Biol. 2014, 10, 744. [CrossRef] [PubMed]

88. Nam, H.; Campodonico, M.; Bordbar, A.; Hyduke, D.R.; Kim, S.; Zielinski, D.C.; Palsson, B.O. A systems approach to predict on-cometabolites via context-specific genome-scale metabolic networks. PLoS Comput. Biol. 2014, 10, 9. [CrossRef]

89. Reimers, A.M.; Reimers, A.C. The steady-state assumption in oscillating and growing systems. J. Theor. Biol. 2016, 406, 176-186. [CrossRef]

90. Marín De Mas, I.; Torrents, L.; Bedia, C.; Nielsen, L.K.; Cascante, M.; Tauler, R. Stoichiometric gene-to-reaction associations enhance model-driven analysis performance: Metabolic response to chronic exposure to aldrin in prostate cancer. BMC Genom. 2019, 20, 1-12. [CrossRef]

91. Orth, J.D.; Thiele, I.; Palsson, B.Ø. What is flux balance analysis? Nat. Biotechnol. 2010, 28, 245-248. [CrossRef]

92. Mahadevan, R.; Schilling, C.H. The effects of alternate optimal solutions in constraint-based genome-scale metabolic models. Metab. Eng. 2003, 5, 264-276. [CrossRef]

93. Lovász, L. Hit-and-run mixes fast. Math. Program. 1999, 86, 443-461. [CrossRef]

94. Price, N.; Schellenberger, J.; Palsson, B.O. Uniform Sampling of Steady-State Flux Spaces: Means to Design Experiments and to Interpret Enzymopathies. Biophys. J. 2004, 87, 2172-2186. [CrossRef]

95. Haraldsdóttir, H.S.; Cousins, B.; Thiele, I.; Fleming, R.M.T.; Vempala, S. CHRR: Coordinate hit-and-run with rounding for uniform sampling of constraint-based models. Bioinformatics 2017, 33, 1741-1743. [CrossRef]

96. Lovász, L.; Vempala, S. Hit-and-run from a corner. SIAM J. Comput. 2004, 35, 985-1005. [CrossRef]

97. Smith, R.L. Efficient Monte Carlo Procedures for Generating Points Uniformly Distributed over Bounded Regions. Oper. Res. 1984, 32, 1296-1308. [CrossRef]

98. Zamboni, N.; Kümmel, A.; Heinemann, M. anNET: A tool for network-embedded thermodynamic analysis of quantitative metabolome data. BMC Bioinform. 2008, 9, 199. [CrossRef] [PubMed]

99. Flamholz, A.; Noor, E.; Bar-Even, A.; Milo, R. eQuilibrator-the biochemical thermodynamics calculator. Nucleic Acids Res. 2011, 40, D770-D775. [CrossRef] [PubMed]

100. Henry, C.S.; Broadbelt, L.J.; Hatzimanikatis, V. Thermodynamics-Based Metabolic Flux Analysis. Biophys. J. 2007, 92, 1792-1805. [CrossRef] [PubMed]

101. Salvy, P.; Fengos, G.; Ataman, M.; Pathier, T.; Soh, K.C.; Hatzimanikatis, V. pyTFA and matTFA: A Python package and a Matlab toolbox for Thermodynamics-based Flux Analysis. Bioinformatics 2018, 35, 167-169. [CrossRef]

102. Tomi-Andrino, C.; Norman, R.; Millat, T.; Soucaille, P.; Winzer, K.; Barrett, D.A.; King, J.; Kim, D.-H. Physicochemical and metabolic constraints for thermodynamics-based stoichiometric modelling under mesophilic growth conditions. PLoS Comput. Biol. 2021, 17, e1007694. [CrossRef] [PubMed]

103. Pries, C.; Razaghi-Moghadam, Z.; Kopka, J.; Nikoloski, Z. Integration of relative metabolomics and transcriptomics time-course data in a metabolic model pinpoints effects of ribosome biogenesis defects on Arabidopsis thaliana metabolism. Sci. Rep. 2021, 11, 1-12. [CrossRef]

104. Tian, M.; Reed, J.L. Integrating Proteomic or Transcriptomic Data into Metabolic Models Using Linear Bound Flux Balance Analysis. Bioinformatics 2018, 34, 3882-3888. [CrossRef] [PubMed]

105. Pandey, V.; Hadadi, N.; Hatzimanikatis, V. Enhanced flux prediction by integrating relative expression and relative metabolite abundance into thermodynamically consistent metabolic models. PLoS Comput. Biol. 2019, 15, e1007036. [CrossRef] [PubMed]

106. Jamialahmadi, O.; Hashemi-Najafabadi, S.; Motamedian, E.; Romeo, S.; Bagheri, F. A benchmark-driven approach to reconstruct metabolic networks for studying cancer metabolism. PLoS Comput. Biol. 2019, 15, e1006936. [CrossRef] [PubMed]

107. Schmidt, B.J.; Ebrahim, A.; Metz, T.O.; Adkins, J.N.; Palsson, B.Ø.; Hyduke, D.R. GIM³ E: Condition-specific models of cellular metab-olism developed from metabolomics and expression data. Bioinformatics 2013, 29, 2900-2908. [CrossRef]

108. Zur, H.; Ruppin, E.; Shlomi, T. iMAT: An integrative metabolic analysis tool. Bioinformatics 2010, 26, 3140-3142. [CrossRef] [PubMed] 
109. Shlomi, T.; Ruppin, E. Computational reconstruction of tissue-specific metabolic models: Application to human liver metabo-lism. Mol. Syst. Biol. 2010, 6, 1-9.

110. Wang, Y.; A Eddy, J.; Price, N.D. Reconstruction of genome-scale metabolic models for 126 human tissues using mCADRE. BMC Syst. Biol. 2012, 6, 153. [CrossRef]

111. Schultz, A.; Qutub, A.A. Reconstruction of Tissue-Specific Metabolic Networks Using CORDA. PLoS Comput. Biol. 2016, 12, e1004808. [CrossRef]

112. Vlassis, N.; Pacheco, M.P.; Sauter, T. Fast Reconstruction of Compact Context-Specific Metabolic Network Models. PLoS Comput. Biol. 2014, 10, e1003424. [CrossRef]

113. Pacheco, M.P.; John, E.; Kaoma, T.; Heinäniemi, M.; Nicot, N.; Vallar, L.; Bueb, J.L.; Sinkkonen, L.; Sauter, T. Integrated metabolic mod-elling reveals cell-type specific epigenetic control points of the macrophage metabolic network. BMC Genom. 2015, 16, 1-24. [CrossRef]

114. Mienda, B.S.; Salihu, R.; Adamu, A.; Idris, S. Genome-scale metabolic models as platforms for identification of novel genes as antimicrobial drug targets. Futur. Microbiol. 2018, 13, 455-467. [CrossRef] [PubMed]

115. Sadhukhan, P.P.; Raghunathan, A. Investigating Host-Pathogen Behavior and Their Interaction Using Genome-Scale Metabolic Network Models. Methods Mol. Biol. 2014, 1184, 523-562. [CrossRef] [PubMed]

116. Raghunathan, A.; Reed, J.; Shin, S.; Palsson, B.; Daefler, S. Constraint-based analysis of metabolic capacity of salmonella typhi-murium during host-pathogen interaction. BMC Syst. Biol. 2009, 3, 38. [CrossRef] [PubMed]

117. Hur, W.; Ryu, J.Y.; Kim, H.U.; Hong, S.W.; Lee, E.B.; Lee, S.Y.; Yoon, S.K. Systems approach to characterize the metabolism of liver cancer stem cells expressing CD133. Sci. Rep. 2017, 7, 45557. [CrossRef]

118. Chelliah, V.; Juty, N.; Ajmera, I.; Ali, R.; Dumousseau, M.; Glont, M.; Hucka, M.; Jalowicki, G.; Keating, S.; Knight-Schrijver, V.; et al. BioModels: Ten-year anniversary. Nucleic Acids Res. 2015, 43, D542-D548. [CrossRef]

119. Robinson, J.L.; Kocabaş, P.; Wang, H.; Cholley, P.-E.; Cook, D.; Nilsson, A.; Anton, M.; Ferreira, R.; Domenzain, I.; Billa, V.; et al. An atlas of human metabolism. Sci. Signal. 2020, 13, eaaz1482. [CrossRef] [PubMed]

120. King, Z.A.; Lu, J.; Dräger, A.; Miller, P.; Federowicz, S.; Lerman, J.A.; Ebrahim, A.; Palsson, B.O.; Lewis, N.E. BiGG Models: A platform for integrating, standardizing and sharing genome-scale models. Nucleic Acids Res. 2016, 44, D515-D522. [CrossRef]

121. Kim, O.D.; Rocha, M.; Maia, P.A. Review of dynamic modeling approaches and their application in computational strain optimi-zation for metabolic engineering. Front. Microbiol. 2018, 9, 1690. [CrossRef] [PubMed]

122. Marin-Hernandez, A.; Gallardo-Perez, J.C.; Rodriguez-Enriquez, S.; Encalada, R.; Moreno-Sanchez, R.; Saavedra, E. Modeling cancer glycolysis. Biochim. Et Biophys. Acta 2011, 1807, 755-767. [CrossRef] [PubMed]

123. Shestov, A.A.; Liu, X.; Ser, Z.; Cluntun, A.A.; Hung, Y.P.; Huang, L.; Kim, D.; Le, A.; Yellen, G.; Albeck, J.G.; et al. Quantitative determinants of aerobic glycolysis identify flux through the enzyme GAPDH as a limiting step. eLife 2014, 3, e03342. [CrossRef] [PubMed]

124. Khazaei, T.; McGuigan, A.P.; Mahadevan, R. Ensemble Modeling of Cancer Metabolism. Front. Physiol. 2012, 3, 135. [CrossRef] [PubMed]

125. Schomburg, I.; Chang, A.; Schomburg, D. BRENDA, enzyme data and metabolic information. Nucleic Acids Res. 2002, 30, 47-49. [CrossRef]

126. Wittig, U.; Golebiewski, M.; Kania, R.; Krebs, O.; Mir, S.; Weidemann, A.; Anstein, S.; Saric, J.; Rojas, I. SABIO-RK: Integration and cu-ration of reaction kinetics data. Lect. Notes Bioinformat. 2006, 4075, 94-103.

127. Jia, G.; Stephanopoulos, G.N.; Gunawan, R. Parameter estimation of kinetic models from metabolic profiles: Two-phase dynamic decoupling method. Bioinformatics 2011, 27, 1964-1970. [CrossRef]

128. Jia, G.; Stephanopoulos, G.; Gunawan, R. Incremental parameter estimation of kinetic metabolic network models. BMC Syst. Biol. 2012, 6, 142. [CrossRef]

129. Murabito, E.; Verma, M.; Bekker, M.; Bellomo, D.; Westerhoff, H.; Teusink, B.; Steuer, R. Monte-Carlo Modeling of the Central Carbon Metabolism of Lactococcus lactis: Insights into Metabolic Regulation. PLoS ONE 2014, 9, e106453. [CrossRef]

130. Miskovic, L.; Béal, J.; Moret, M.; Hatzimanikatis, V. Uncertainty reduction in biochemical kinetic models: Enforcing desired model properties. PLoS Comput. Biol. 2019, 15, e1007242. [CrossRef]

131. Mišković, L.; Hatzimanikatis, V. Modeling of uncertainties in biochemical reactions. Biotechnol. Bioeng. 2010, 108, 413-423. [CrossRef]

132. Stanford, N.J.; Lubitz, T.; Smallbone, K.; Klipp, E.; Mendes, P.; Liebermeister, W. Systematic Construction of Kinetic Models from Genome-Scale Metabolic Networks. PLoS ONE 2013, 8, e79195. [CrossRef] [PubMed]

133. Soh, K.C.; Miskovic, L.; Hatzimanikatis, V. From network models to network responses: Integration of thermodynamic and kinetic properties of yeast genome-scale metabolic networks. FEMS Yeast Res. 2011, 12, 129-143. [CrossRef] [PubMed]

134. Khodayari, A.; Zomorrodi, A.R.; Liao, J.; Maranas, C.D. A kinetic model of Escherichia coli core metabolism satisfying multiple sets of mutant flux data. Metab. Eng. 2014, 25, 50-62. [CrossRef]

135. Chowdhury, A.; Zomorrodi, A.R.; Maranas, C.D. k-OptForce: Integrating Kinetics with Flux Balance Analysis for Strain Design. PLoS Comput. Biol. 2014, 10, e1003487. [CrossRef]

136. Volkova, S.; Matos, M.R.A.; Mattanovich, M.; Marín de Mas, I. Metabolic modelling as a framework for metabolomics data inte-gration and analysis. Metabolites 2020, 10, 303. [CrossRef]

137. Tran, L.M.; Rizk, M.L.; Liao, J.C. Ensemble Modeling of Metabolic Networks. Biophys. J. 2008, 95, 5606-5617. [CrossRef] 
138. Miskovic, L.; Hatzimanikatis, V. Production of biofuels and biochemicals: In need of an ORACLE. Trends Biotechnol. 2010, 28, 391-397. [CrossRef]

139. Saa, P.; Nielsen, L.K. A general framework for thermodynamically consistent parameterization and efficient sampling of enzy-matic reactions. PLoS Comput. Biol. 2015, 11, e1004195. [CrossRef] [PubMed]

140. Gopalakrishnan, S.; Dash, S.; Maranas, C. K-FIT: An accelerated kinetic parameterization algorithm using steady-state fluxomic data. Metab. Eng. 2020, 61, 197-205. [CrossRef] [PubMed]

141. Heirendt, L.; Arreckx, S.; Pfau, T.; Mendoza, S.N.; Richelle, A.; Heinken, A.; Haraldsdóttir, H.S.; Wachowiak, J.; Keating, S.M.; Vlasov, V.; et al. Creation and analysis of bio-chemical constraint-based models using the COBRA toolbox v.3.0. Nat. Protoc. 2019, 14, 639-702. [CrossRef] [PubMed]

142. Ebrahim, A.; Lerman, J.A.; Palsson, B.O.; Hyduke, D.R. COBRApy: COnstraints-Based Reconstruction and Analysis for Python. BMC Syst. Biol. 2013, 7, 74. [CrossRef] [PubMed]

143. Heirendt, L.; Thiele, I.; Fleming, R.M.T. DistributedFBA.jl: High-level, high-performance flux balance analysis in Julia. Bioinformatics 2017, 33, 1421-1423. [CrossRef] [PubMed]

144. Mendoza, S.N.; Olivier, B.G.; Molenaar, D.; Teusink, B. A systematic assessment of current genome-scale metabolic reconstruction tools. Genome Biol. 2019, 20, 1-20. [CrossRef] [PubMed]

145. Kotze, H.L.; Armitage, E.G.; Sharkey, K.J.; Allwood, J.W.; Dunn, W.B.; Williams, K.J.; Goodacre, R. A novel untargeted metabolomics correlation-based network analysis incorporating human metabolic reconstructions. BMC Syst. Biol. 2013, 7, 107. [CrossRef]

146. Klamt, S.; Saez-Rodriguez, J.; Gilles, E.D. Structural and functional analysis of cellular networks with CellNetAnalyzer. BMC Syst. Biol. 2007, 1, 2. [CrossRef] [PubMed]

147. Grafahrend-Belau, E.; Klukas, C.; Junker, B.H.; Schreiber, F. FBA-SimVis: Interactive visualization of constraint-based metabolic models. Bioinformatics 2009, 25, 2755-2757. [CrossRef]

148. Rocha, I.; Maia, P.; Evangelista, P.; Vilaça, P.; Soares, S.; Pinto, J.P.; Nielsen, J.; Patil, K.R.; Ferreira, E.C.; Rocha, M. OptFlux: An open-source software platform for in silico metabolic engineering. BMC Syst. Biol. 2010, 4, 45. [CrossRef]

149. Gelius-Dietrich, G.; Desouki, A.A.; Fritzemeier, C.J.; Lercher, M.J. sybil-Efficient constraint-based modelling in R. BMC Syst. Biol. 2013, 7, 125. [CrossRef]

150. Olivier, B.G.; Rohwer, J.; Hofmeyr, J.-H.S. Modelling cellular systems with PySCeS. Bioinformatics 2004, 21, 560-561. [CrossRef]

151. Gevorgyan, A.; Bushell, M.E.; Avignone-Rossa, C.; Kierzek, A.M. SurreyFBA: A command line tool and graphics user interface for constraint-based modeling of genome-scale metabolic reaction networks. Bioinformatics 2010, 27, 433-434. [CrossRef] [PubMed]

152. Hoppe, A.; Hoffmann, S.; Gerasch, A.; Gille, C.; Holzhütter, H.-G. FASIMU: Flexible software for flux-balance computation series in large metabolic networks. BMC Bioinform. 2011, 12, 28. [CrossRef]

153. Boele, J.; Olivier, B.G.; Teusink, B. FAME, the Flux Analysis and Modeling Environment. BMC Syst. Biol. 2012, 6, 8. [CrossRef] [PubMed]

154. Latendresse, M.; Karp, P.D. Web-based metabolic network visualization with a zooming user interface. BMC Bioinform. 2011, 12, 176. [CrossRef] [PubMed]

155. Arkin, A.P.; Cottingham, R.; Henry, C.S.; Harris, N.L.; Stevens, R.L.; Maslov, S.; Dehal, P.; Ware, D.; Perez, F.; Canon, S.; et al. KBase: The United States Department of Energy Systems Biology Knowledgebase. Nat. Biotechnol. 2018, 36, 566-569. [CrossRef]

156. Karlsen, E.; Schulz, C.; Almaas, E. Automated generation of genome-scale metabolic draft reconstructions based on KEGG. BMC Bioinform. 2018, 19, 1-11. [CrossRef]

157. Aite, M.; Chevallier, M.; Frioux, C.; Trottier, C.; Got, J.; Cortés, M.P.; Mendoza, S.N.; Carrier, G.; Dameron, O.; Guillaudeux, N.; et al. Traceability, reproducibility and wiki-exploration for 'à-La-Carte' reconstructions of genome-scale metabolic models. PLoS Comput. Biol. 2018, 14, 1-25. [CrossRef]

158. Machado, D.; Andrejev, S.; Tramontano, M.; Patil, K.R. Fast automated reconstruction of genome-scale metabolic models for mi-crobial species and communities. Nucleic Acids Res. 2018, 46, 7542-7553. [CrossRef]

159. Hanemaaijer, M.; Olivier, B.G.; Röling, W.F.M.; Bruggeman, F.; Teusink, B. Model-based quantification of metabolic interactions from dynamic microbial-community data. PLoS ONE 2017, 12, e0173183. [CrossRef] [PubMed]

160. Henry, C.S.; DeJongh, M.; A Best, A.; Frybarger, P.M.; Linsay, B.; Stevens, R.L. High-throughput generation, optimization and analysis of genome-scale metabolic models. Nat. Biotechnol. 2010, 28, 977-982. [CrossRef] [PubMed]

161. Karp, P.D.; Latendresse, M.; Paley, S.M.; Krummenacker, M.; Ong, Q.D.; Billington, R.; Kothari, A.; Weaver, D.; Lee, T.; Subhraveti, P.; et al. Pathway tools version 19.0 update: Software for pathway/genome informatics and systems biology. Brief Bioinform. 2016, 17, 877-890. [CrossRef]

162. Dias, O.; Rocha, M.; Ferreira, E.C.; Rocha, I. Reconstructing genome-scale metabolic models with merlin. Nucleic Acids Res. 2015, 43, 3899-3910. [CrossRef] [PubMed]

163. Pitkänen, E.; Jouhten, P.; Hou, J.; Syed, M.F.; Blomberg, P.; Kludas, J.; Oja, M.; Holm, L.; Penttilä, M.; Rousu, J.; et al. Comparative Genome-Scale Reconstruction of Gapless Metabolic Networks for Present and Ancestral Species. PLoS Comput. Biol. 2014, 10, e1003465. [CrossRef] [PubMed]

164. Pabinger, S.; Snajder, R.; Hardiman, T.; Willi, M.; Dander, A.; Trajanoski, Z. MEMOSys 2.0: An update of the bioinformatics database for genome-scale models and genomic data. Database 2014, 2014, bau004. [CrossRef] [PubMed] 
165. Liao, Y.-C.; Tsai, M.-H.; Chen, F.-C.; Hsiung, C.A. GEMSiRV: A software platform for GEnome-scale metabolic model simulation, reconstruction and visualization. Bioinformatics 2012, 28, 1752-1758. [CrossRef]

166. Cottret, L.; Frainay, C.; Chazalviel, M.; Cabanettes, F.; Gloaguen, Y.; Camenen, E.; Jourdan FMerlet, B.; Heux, S.; Portais, J.C.; Poupin, N.; et al. MetExplore: Collaborative edition and exploration of metabolic networks. Nucleic Acids Res. 2018, 46, 495-502. [CrossRef]

167. Thorleifsson, S.G.; Thiele, I. rBioNet: A COBRA toolbox extension for reconstructing high-quality biochemical networks. Bioinformatics 2011, 27, 2009-2010. [CrossRef]

168. Latendresse, M.; Krummenacker, M.; Trupp, M.; Karp, P.D. Construction and completion of flux balance models from pathway databases. Bioinformatics 2012, 28, 388-396. [CrossRef] [PubMed]

169. Apaolaza, I.; San José-Eneriz, E.; Agirre, X.; Prósper, F.; Planes, F.J. COBRA methods and metabolic drug targets in cancer. Mol. Cell. Oncol. 2018, 5, 10-12. [CrossRef] [PubMed]

170. Turanli, B.; Zhang, C.; Kim, W.; Benfeitas, R.; Uhlen, M.; Arga, K.Y.; Mardinoglu, A. Discovery of therapeutic agents for prostate cancer using genome-scale metabolic modeling and drug repositioning. EBioMedicine 2019, 42, 386-396. [CrossRef]

171. Zhang, C.; Ji, B.; Mardinoglu, A.; Nielsen, J.; Hua, Q. Logical transformation of genome-scale metabolic models for gene level ap-plications and analysis. Bioinformatics 2015, 31, 2324-2331. [CrossRef]

172. Ortmayr, K.; Dubuis, S.; Zampieri, M. Metabolic profiling of cancer cells reveals genome-wide crosstalk between transcriptional regulators and metabolism. Nat. Commun. 2019, 10, 1-13. [CrossRef] [PubMed]

173. Raškevičius, V.; Mikalayeva, V.; Antanavičiūte, I.; Ceslevičienė, I.; Skeberdis, V.A.; Kairys, V.; Bordel, S. Genome scale metabolic models as tools for drug design and personalized medicine. PLOS ONE. 2018, 13, 1-14. [CrossRef]

174. Wishart, D.S.; Feunang, Y.D.; Guo, A.C.; Lo, E.J.; Marcu, A.; Grant, J.R.; Sajed, T.; Johnson, D.; Li, C.; Sayeeda, Z.; et al. DrugBank 5.0: A Major Update to the DrugBank Database for 2018. Nucleic Acids Res. 2018, 46, D1074-D1082. [CrossRef] [PubMed]

175. O’Boyle, N.M.; Banck, M.; James CAMorley, C.; Vandermeersch, T.; Hutchison, G.R. Open Babel: An open chemical toolbox. J. Cheminform. 2011, 3, 33. [CrossRef] [PubMed]

176. Goldman, A.; Khiste, S.; Freinkman, E.; Dhawan, A.; Majumder, B.; Mondal, J.; Pinkerton, A.B.; Eton, E.; Medhi, R.; Chandrasekar, V.; et al. Targeting tumor phenotypic plasticity and metabolic remodeling in adaptive cross-drug tolerance. Sci. Signal. 2019, 12, eaas8779. [CrossRef] [PubMed]

177. Mazat, J.-P.; Ransac, S. The Fate of Glutamine in Human Metabolism. The Interplay with Glucose in Proliferating Cells. Metab. 2019, 9, 81. [CrossRef]

178. Uhlén, M.; Zhang, C.; Lee, S.; Sjöstedt, E.; Fagerberg, L.; Bidkhori, G.; Benfeitas, R.; Arif, M.; Liu, Z.; Edfors, F.; et al. A pathology atlas of the human cancer transcriptome. Science 2017, 357, eaan2507. [CrossRef]

179. Zhang, C.; Aldrees, M.; Arif, M.; Li, X.; Mardinoglu, A.; Aziz, M.A. Elucidating the Reprograming of Colorectal Cancer Metabolism Using Genome-Scale Metabolic Modeling. Front. Oncol. 2019, 9, 681. [CrossRef]

180. Resendis-Antonio, O.; Gonzalez-Torres, C.; Jaime-Muñoz, G.; Hernandez-Patiño, C.E.; Salgado-Muñoz, C.F. Modeling metabolism: A window toward a comprehensive interpretation of networks in cancer. Semin. Cancer Biol. 2015, 30, 79-87. [CrossRef] [PubMed]

181. Vazquez, A.; Liu, J.; Zhou, Y.; Oltvai, Z.N. Catabolic efficiency of aerobic glycolysis: The Warburg effect revisited. BMC Syst. Biol. 2010, 4, 58. [CrossRef]

182. Asgari, Y.; Zabihinpour, Z.; Salehzadeh-Yazdi, A.; Schreiber, F.; Masoudi-Nejad, A. Alterations in cancer cell metabolism: The Warburg effect and metabolic adaptation. Genomics 2015, 105, 275-281. [CrossRef]

183. Magnusdottir, S.; Heinken, A.; Kutt, L.; Ravcheev, D.; Bauer, E.; Noronha, A.; Greenhalgh, K.; Jäger, C.; Baginska, J.; Wilmes, P.; et al. Generation of genome-scale metabolic reconstructions for 773 members of the human gut microbiota. Nat. Biotechnol. 2017, 35, 81-89. [CrossRef] [PubMed]

184. Bauer, E.; Thiele, I. From metagenomic data to personalized in silico microbiotas: Predicting dietary supplements for Crohn's disease. NPJ Syst. Biol. Appl. 2018, 4, 1-9. [CrossRef]

185. Diener, C.; Gibbons, S.M.; Resendis-Antonio, O. MICOM: Metagenome-Scale Modeling To Infer Metabolic Interactions in the Gut Microbiota. mSystems 2020, 5, 00606-19. [CrossRef]

186. Thiele, I.; Sahoo, S.; Heinken, A.; Hertel, J.; Heirendt, L.; Aurich, M.K.; Fleming, R.M. Personalized whole-body models integrate me-tabolism, physiology, and the gut microbiome. Mol. Syst. Biol. 2020, 16, e8982. [CrossRef]

187. Wu, F.; Fan, J.; He, Y.; Xiong, A.; Yu, J.; Li, Y.; Zhang, Y.; Zhao, W.; Zhou, F.; Li, W.; et al. Single-cell profiling of tumor heterogeneity and the microenvironment in advanced non-small cell lung cancer. Nat. Commun. 2021, 12, 1-11. [CrossRef]

188. Lin, W.; Noel, P.; Borazanci, E.H.; Lee, J.; Amini, A.; Han, I.W.; Heo, J.S.; Jameson, G.S.; Fraser, C.; Steinbach, M.; et al. Single-cell transcriptome analysis of tumor and stromal compartments of pancreatic ductal adenocarcinoma primary tumors and metastatic lesions. Genome Med. 2020, 12, 1-14. [CrossRef] [PubMed]

189. Dominguez, C.X.; Müller, S.; Keerthivasan, S.; Koeppen, H.; Hung, J.; Gierke, S.; Breart, B.; Foreman, O.; Bainbridge, T.W.; Castiglioni, A.; et al. Single-Cell RNA Sequencing Reveals Stromal Evolution into LRRC15+ Myofibroblasts as a Determinant of Patient Response to Cancer Immunotherapy. Cancer Discov. 2020, 10, 232-253. [CrossRef] [PubMed]

190. Damiani, C.; Di Filippo, M.; Pescini, D.; Maspero, D.; Colombo, R.; Mauri, G. popFBA: Tackling intratumour heterogeneity with Flux Balance Analysis. Bioinformatics 2017, 33, i311-i318. [CrossRef] 
191. Damiani, C.; Maspero, D.; Di Filippo, M.; Colombo, R.; Pescini, D.; Graudenzi, A.; Westerhoff, H.V.; Alberghina, L.; Vanoni, M.; Mauri, G. Integration of single-cell RNA-seq data into population models to characterize cancer metabolism. PLoS Comput. Biol. 2019, 15, e1006733. [CrossRef]

192. Kang, Y.P.; Ward, N.; DeNicola, G.M. Recent advances in cancer metabolism: A technological perspective. Exp. Mol. Med. 2018, 50, 1-16. [CrossRef]

193. Durinikova, E.; Buzo, K.; Arena, S. Preclinical models as patients' avatars for precision medicine in colorectal cancer: Past and future challenges. J. Exp. Clin. Cancer Res. 2021, 40,1-17. [CrossRef]

194. Karta, J.; Bossicard, Y.; Kotzamanis, K.; Dolznig, H.; Letellier, E. Mapping the metabolic networks of tumor cells and can-cerassociated fibroblasts. Cells 2021, 10, 304. [CrossRef] [PubMed]

195. Capuani, F.; De Martino, D.; Marinari, E.; De Martino, A. Quantitative constraint-based computational model of tumor-to-stroma coupling via lactate shuttle. Sci. Rep. 2015, 5, 11880. [CrossRef]

196. Shan, M.; Dai, D.; Vudem, A.; Varner, J.D.; Stroock, A. Multi-scale computational study of the Warburg effect, reverse Warburg effect and glutamine addiction in solid tumors. PLoS Comput. Biol. 2018, 14, e1006584. [CrossRef] [PubMed]

197. De Goede, K.; Driessen, A.; Bossche, J.V.D. Metabolic Cancer-Macrophage Crosstalk in the Tumor Microenvironment. Biology 2020, 9, 380. [CrossRef] [PubMed]

198. Rath, M.; Mã $\frac{1}{4}$ Ller, I.; Kropf, P.; Closs, E.I.; Munder, M. Metabolism via Arginase or Nitric Oxide Synthase: Two Competing Arginine Pathways in Macrophages. Front. Immunol. 2014, 5, 532. [CrossRef]

199. Li, X.; Jolly, M.K.; George, J.; Pienta, K.J.; Levine, H. Computational Modeling of the Crosstalk Between Macrophage Polarization and Tumor Cell Plasticity in the Tumor Microenvironment. Front. Oncol. 2019, 9, 10. [CrossRef]

200. Puniya, B.L.; Amin, R.; Lichter, B.; Moore, R.; Ciurej, A.; Bennett, S.J.; Shah, A.R.; Barberis, M.; Helikar, T. Integrative computational approach identifies drug targets in CD4+ T-cell-mediated immune disorders. NPJ Syst. Biol. Appl. 2021, 7, 4. [CrossRef] 